\title{
MECHANISMS OF ENERGY ABSORPTION IN SPECIAL DEVICES FOR USE IN EARTHQUAKE RESISTANT STRUCTURES
}

\author{
J. M. Kelly*, R. I. Skinner** and A. J. Heine**
}

\begin{abstract}
A structure designed to resist earthquake attack must have a capacity to dissipate kinetic energy induced by. the ground motion. In most structures this energy absorption is developed in the vicinity of beam to column connections. Recent research has shown that connections are not reliable when subject to cyclic loading, such as results from earthquake attack. Connections in steel frames deteriorate due to local instabilities in adjacent flanges, and in reinforced concrete frames alternating shear loads produce diagonal tension and bond failures which progressively reduce the strength of the connection.

Much work in building research and earthquake engineering in laboratories throughout the world is directed toward increasing the reliability and energy absorption capacity of structural connections. In this paper an alternative approach to this problem is described. This approach is to separate the load carrying function of the structure from the energy absorbing function and to ask if special devices could be incorporated into the structure with the sole purpose of absorbing the kinetic energy generated in the structure by earthquake attack.

To determine whether such devices are feasible a study has been undertaken of three essentially different mechanisms of energy absorption. These mechanisms all utilized the plastic deformation of mild steel. The included the rolling of strips, torsion of square and rectangular bars, and the flexure of short thick beams. The se mechanisms were selected for intensive study since they were basic to three different types of device each of which was designed for a separate mode of operation in a structural system.

The characteristics of these mechanisms which were of primary importance in this study were the load displacement relations, the energy absorption capacity and the fatigue resistance. This information was obtained with a view to the development of devices for specific structural applications.

This report describes the tests used to explore the basic mechanisms and the data obtained. It also includes a brief description of tests on scale models of a device which was designed to be located in the piers of a reinforced concrete rail way bridge.

It has been shown by the tests that the plastic torsion of mild steel is an extremely efficient mechanism for the absorption of energy. It was found that at plastic strains in the range $3 \%$ to $12 \%$ it was possible to develop energy dissipation of the order of 2000-7500 1b in/in 3 per cycle $(14-50 \mathrm{x}$ $10^{6} \mathrm{~N} / \mathrm{M}^{2}$ per cycle) with lifetimes within the range of 1000 to 100 cycles. It was also shown that the mode of failure in torsion is an extremely favourable one for use in an energy absorbing device in that it took the form of a gradual decay. The other two mechanisms studied were both less efficient and less reliable than torsion and had capacities of 500-2000 lb in/in 3 per cycle $\left(3.5-14 \times 10^{6} \mathrm{~N} / \mathrm{M}^{2}\right.$ per cycle) and life times of around 200 to 20 cycles. Nevertheless they lend themselves to more compact devices than does the torsional mechanism and furthermore the devices may be located in regions in a structure where they are readily accessible for replacement after attack.
\end{abstract}

\section{INTRODUCTION}

The attack of an earthquake on a structure is through the interaction of the oscillatory ground acceleration and the inertia of the

* On leave from Division of Structural Engineering and structural Mechanics, Department of Civil Engineering, University of California, Berkeley, California.

* Engineering Seismology Section, Physics and Engineering Laboratory, D.S.I.R., Lower Hutt, N.z. structure itself, and as a result the extent of the attack depends on the dynamic response of the structure and the frequency content and duration of the ground motion. Since most highrise structures have natural frequencies in the same range as the dominant frequencies of the ground motion it is generally agreed $(1,2,3)$ that to resist the attack of a major earthquake it is necessary to accept a degree of plastic action in the structure. This plastic action, which comes into play when the normal range of deflection is exceeded, gives a large increase in mechanical damping 
64

and permits deflections which exceed those of elastic design. The damping provided by the yielding of some elements in the structure prevents a resonant build up of deflection thus limiting the maximum deformations to less than would occur in a conventionally damped system.

The current approach to design is to attempt to combine this plastic action, usually referred to as ductility, with a certain degree of flexibility. Flexibility is considered necessary to reduce the internal forces produced by the ground acceleration and to reduce the accelerations imposed on the contents and occupants of the structure. Ductility is defined to be the ratio of the maximum deformation prior to collapse to that at initial yield. In a sense it represents the reserve deformability beyond the elastic range before unacceptable damage occurs. Thus in general terms we may say that the design philosophy is to combine flexibility and ductility to minimize the internal forces and to prevent collapse if the elastic deformation of the system is exceeded.

The design approach on the basis of most building codes is to replace the earthquake attack by nominally equivalent lateral loads derived by the use of empirical formulae and to proportion the elements of the structure particularly the moment resisting beam column connections to carry these horizontal loads. The structure resists the earthquake attack in an entirely different way. As the ground motion feeds energy into the structure, energy dissipating elements act to minimize the excursions and prevent collapse. Thus the concept of ductility based on unidirectional loading is unsatisfactory. It is important to emphasize the cyclic nature of the earthquake attack on a structure. In the 1964 Alaskan earthquake for example, the ground motion had a predominant period around 1 sec, which is also a typical fundamental period for a high rise building and a duration of at least three minutes. In such a case the energy absorbing mechanisms in the structure could be subject to around 200 cycles of loading. The Alaskan earthquake was, of course, an example of an earthquake of exceptionally long duration, the number of cycles for a more typical major earthquake and accompanying aftershocks would be perhaps 100 cycles.

Recent tests involving cyclic loading on standard beam-column connections for steel frames by popov et al $(4,5)$ have shown that plastic instability in flanges adjacent to the connections has the effect of reducing the energy absorbing capacity of the connections and that this instability does not appear in unidirectional loading but only after reversal. Tests by Bresler and Bertero (6) on cyclic loading of reinforced concrete beams have shown that their stiffness and strength decrease when subject to cyclic loading. The implication of these results is that reinforced concrete structures designed according to conventional practice suffer from a rapid deterioration under cyclic loading. Thus ductility, reflecting as it does reserve under unidirectional loading, does not adequately represent the reserve against cyclic loading if the system contains elements which deteriorate under cyclic loading. connections provides adequate flexibility but does so at the expense of large interstory drift in the lower floors. The energy absorption is developed entirely in the beam column connections which are difficult to design for cyclic loading. The high cost associated with steel frame construction has led to the development of reinforced concrete frames using what Blume (?) has called ductile concrete. This type of design suffers from a reduced flexibility and an increased weight leading to high internal forces anu, although it is possible by careful design and high quality construction techniques to enhance the energy absorbing capacity of the structure, it is not possible to provide very many cycles of plastic action without damage to the concrete. In addition all structural frames in which the energy absorbing capacity of the system is provided by plastic action at connections have the disadvantage that the presence of plastic hinges at the joints can allow a severe interaction of non-earthquake loads and the earthquake generated displacements.

Composite buildings in which a light frame is braced against lateral forces by a core or a system of shear walls have at first sight a number of distinct advantages over moment resisting frames. However, the concrete core and the steel frame are badly matched in terms of stiffness and interstory deflection. The different patterns of displacement require that the lateral loads, apportioned to each element to produce equal displacements, are carried mainly by the core in the lower storeys and by the frame in the upper storeys. It has been pointed out by Newmark (1) that this can lead to a structure which is insufficiently flexible in the lower storeys. Also the energy absorbing capacity of the core is uncertain and that of the frame cannot be developed. There are also problems of detailed design and constructional practice to ensure the adequate interaction of the core and the frame.

Other structural forms such as those with prestressed members and those of shell form have a limited capacity for energy absorption, as have bridge pier bearings.

In view of the difficulty of providing reliable energy absorbing capacity in most structural forms it seems logical to ask if special devices could be built into the structure with the purpose of providing solely for the absorption of kinetic energy generated in the structure by earthquake induced ground motion. The provision of a system of such devices separate from the main load-carrying capacity of the structure would have a number of advantages to of set the additional cost of the devices. The main structure would operate under simpler and less severe conditions and its static and dynamic response could be analysed using elastic methods. A reduction in design effort and constructional cost is also possible through the use of simpler beam column connections which would not now be called upon to provide the energy absorbing capacity of the structure. A better distribution of deformation might be possible with such a design approach.

The energy absorbing devices could be designed to operate at levels of seismic intensity lower than those at which structures designed according to current practice are damaged and could be replaceable when subject to a major earthquake. The necessity to design for large plastic deformations of structural components 
imposes severe constraints on the designers in terms of materials, detailing and structural forms. A source of difficulty is the imposed loads which components must withstand while undergoing plastic deformations. When special structural components are introduced with the primary function of absorbing energy there may be increased reliability, lower costs, and a wider range of design possibilities. The basic attraction of the concept lies in concentration of the inelastic deformation in a replaceable device specifically designed to provide energy absorption.

The specification for such a device might be expressed in the following way. It should not be involved in transmitting the static loads of the structure; it should operate only under earthquake attack; it should perform at least 100 cycles of energy absorption without deterioration and should be replaceable when subject to a major earthquake.

\section{THE ENERGY ABSORBER AS A STRUCTURAL ELEMENT}

An approach to structural design somewhat similar to that proposed here has been used in Japan, where a number of tall buildings have been designed with reinforced concrete panels. Each panel has a set of vertical slits as a result of which the panel acts as a series of reinforced concrete columns. When a panel is deformed by interstory deflection, hinges are formed at the top and bottom of each effective column thus absorbing energy (8). This appears to be the first use of components with the primary function of absorbing earthquake induced energy, and while constituting an advance in aseismic design the use of these slit panels does entail certain disadvantages. They add substantially to the weight of the structure and consequently to the internal forces generated by the earthquake motion. Moreover, as mentioned before, reinforced concrete suffers a rapid deterioration under cyclic plastic deformation. It would seem more logical to use reinforced concrete to carry vertical loads and use plastically deforming steel to dissipate energy.

In the course of the present project a number of basic mechanisms of energy absorption have been studied. In each case these utilized the plastic deformation of mild steel, and included the rolling (with bending) of flat strips, torsion of square and rectangular bars, flexure of beams of rectangular section and combinations of these. The aim of the tests was to determine the energy absorption capacity, the fatigue resistance, and the stability of the material when loaded in the above ways. A description of the test procedures and results will be given in later sections.

On the basis of the results of these tests three main types of energy absorbing device have been developed and tested. These three types use essentially different mechanisms of energy dissipation and are envisaged as being applicable to three distinct situations in structural systems. The devices are as follows:

TYPE A. This device makes use of the rolling (bending) of flat strips of mild steel. It is designed to be located between flexibly based shear walls in a composite building. The device operates between adjacent surfaces whose relative motion is directed parallel to each other.
TYPE B. This device uses a combination of tor sion and bending (with torsion predominating) of square or rectangular bars. It operates between surfaces moving toward and away from each other. The load capacity of this device can be made very high and it is designed to be used in foundations or in association with a shear wall system.

TYPE C. This device utilizes the flexural behaviour of short rectangular beams and the physical dimensions of the device make it suitable for insertion in diagonal bracing in steel or reinforced concrete frames to provide the energy absorption normally developed in the vicinity of the beam column connections.

Figs. 1 (a) (b) and (c) are schematic representations of the three devices showing their mode of operation.

Typical structural systems in which these devices may be used are shown in Fig. 2. In addition to those shown other combinations are possible in which all three devices are used concurrently.

The present report will be concerned with the study of the basic mechanisms of energy absorption from which the above devices will be developed. The development of the devices will be reported in a subsequent paper.

To obtain an estimate of the magnitude of the energy absorption which these devices could be called upon to provide in a typical structural situation we consider here a very simple model of a vibrating system including hysteretic damping. We consider further that the system, of mass $M$ and period $T$, is subject to impulsive excitation which is synchronous with free vibrations of the system and that the damping mechanism which for simplicity will be assumed to be of Coulomb type, is large enough to damp out each impulsively generated oscillation in exactly one cycle. This is not intended to be a representation of an earthquake induced motion but is used to avoid the difficulties of numerical integration necessary if actual earthquake excitation is used. It is considered that if the damping is adequate to kill each vibration in one cycle it will be adequate to prevent the resonant build-up of earthquake induced vibrations in an actual attack.

It is usual to specify a maximum level of acceleration in the aseismic design of a structure. We note that an oscillator of period $T$ experiencing a maximum acceleration a

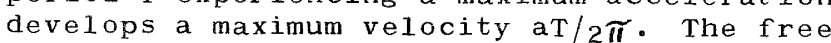
vibrations of an oscillator damped by coulomb friction are conveniently represented by a phase plane plot as shown in Fig. 3. The axes are displacement and velocity/frequency and a solution which takes the system from initial conditions of specified velocity and zero displacement to the final conditions of zero velocity and displacement is shown in the figure. The quantity $r_{0}$ which defines centres in the hodograph is given by

$$
r_{0}=F_{0 / K}
$$

where $F_{0}$ is the frictional force and $K$ the elastic stiffness.

It is clear from the diagram that 
66

$$
r_{0}=\frac{1}{\sqrt{24}} \frac{a T^{2}}{(2 \pi)^{2}}
$$

and

$$
F_{0}=\frac{K}{\sqrt{24}} \frac{a T^{2}}{(2 \pi)^{2}}=\frac{1}{\sqrt{24}} M a
$$

The maximum displacement is

$$
4 r_{0}=\frac{4}{\sqrt{24}} \frac{a T^{2}}{(2 \pi)^{2}}
$$

For the purpose of this example we take $T$ $=1$ sec, typical of a 20-storey high rise structure and assume a floor weight of $10^{6} 1 \mathrm{bs}$ $(450,000 \mathrm{~kg})$. The design acceleration for a building of this period may be around $0.2 \mathrm{~g}$. Thus the required $F_{0}$ is 40,000 lbs $(180,000 \mathrm{~N})$ and the displacement $1 \frac{1}{\mathrm{~g}}$ inch $(3.8 \mathrm{~cm})$. The total energy dissipation requirement per cycle is of the order of $12 \mathrm{~F}_{\mathrm{o}} \mathrm{r}_{\mathrm{o}}=180,000$ bin $(6800$ NM).

The displacement of $1 \frac{1}{2}$ inch is somewhat large as an interstory drift; on a $10 \mathrm{ft}$ storey weight it represents a relative displacement of 1 in 80 . Taking 1 inch $(2.54 \mathrm{~cm})$ as a more reasonable number this would increase the required force to $60,000 \mathrm{lb}(270,000 \mathrm{~N})$. If this capacity were to be provided using devices of type $c$ inserted in diagonal bracing it is probable that two devices would be used; if it were provided by a device of type A located at each storey level the force required would be reduced in the ratio of the shear wall width to the storey height which ratio might be of the order of one half. Thus for these devices $30,0001 \mathrm{~b}(135,000 \mathrm{~N})$ would seem to be a reasonable estimate of the magnitude of the forces required.

It is not so easy to estimate the requirements for a device of type B which might be used in foundations or in seismic gaps between non-synchronous parts of a structure. However, the use of a device of this type has been proposed for a bridge project of the New Zealand Railways. For this reason a detailed analysis of the structural system proposed for the bridge and including an energy absorbing device of this type has been made and is given In detall by J. L. Beck and R. I. Skinner (9). to which reverence may be made for the details of the analysis. A brief summary of those aspects of the project which relate to energy absorption devices will be given here.

The New zealand Railways is at present engaged in a program intended to replace conventional steol rallway viaducts with low maintenance reinforced concrete structures. The example shown in Fig. 4 is typical of these new designs. This particular example consists of simply supported beams of $200 \cdot(61 \mathrm{M})$ span carried on $21^{\circ}(65.5 \mathrm{M})$ high A-frames with a base spread of $40^{\circ}(12.2 \mathrm{M})$. The structure was initially proportioned on the basis of the standard dead and live loads with a provision for earthquake loading of $12 \%$ dead load.

As pointed out earlier in this report, a disadvantage of reinforced concrete is its inability to provide plastic action without rapid deterioration. To provide some plastic action in the system the Railways engineers suggested that steel pins be included in the pler legs near the base. The full loads, static and dynamic, in the legs would be transmitted through the pins and overload inducing yielding of the pins would provide the plastic action. A detailed dynamic analysis of the system including the pins enabled the response of the system to a typical earthquake to be computed $(10)$ and it was found that there were certain difficulties in providing adequate energy absorption and that excessively high tension stresses could be developed in the legs. These difficulties are largely due to the fact that the pins have to be able to transmit the entire static 1oad.

A modification of the system to allow the leg to step off its base was proposed. Here the problem of tension in the leg is removed but the system is almost entirely without energy absorption or even normal levels of damping. Under certain excitations excessively high displacements could be developed and the structure could vibrate for a considerable period of time after a disturbance. To provide energy absorption in the stepping bridge it was proposed by engineers at PEL to use torsional energy absorbers in the legs of each frame. The devices would be arranged in pairs on each side of a central guide pin, and would be located in such a way that they were operative only when the leg was stepping of $f$ its base. A computer analysis (9) of the proposed system has shown that two devices per leg, each providing around 30,0001 bs $(135,000 \mathrm{~N})$ with a displacement of around 1 "l $(2.5 \mathrm{~cm})$ would be required to bring the earthquake induced oscillations to an acceptable level.

It will be shown in the later sections that the energy absorbing capacity (in terms of energy disstpated per unit volume of material) of mild steel is so large that these energy absorption requirements can be developed by devices of fairly modest dimensions.

\section{TEST RESULTS ON BASIC MECHANISMS OF ENERGY} ABSORPTION

\section{(a) Rolling (Bending) of Thin U-shaped Strips}

The mechanism of energy absorption in the U-shaped strips is very simple. The strip is initially in a semi-circular form with two equal straight sections on either side. When one side is moved relative to the other the semi-circular portion rolls along the strip and work is done at the two points where the radius of curvature is changed from straight to the radius of the semi-circle and then from this radius to straight. Thus at any instant the energy dissipation is concentrated at two transverse surfaces but these two surfaces move along the strip. The maintenance of the semi-circular shape can be enhanced by including a roller held in position in such a way that it can move with the semi-circular portion but this is not essential for the energy dissipation process.

The investigation of the energy absorption of the U-shaped strips utilized the test set-up shown in Fig. 5. Alternating tension and compression loads were applied to the central bar of the double strip system, by a standard Instron testing machine. For the purpose of interpreting the results it is convenient to refer to Fig. 6 which shows the loading device in detail. The steel strips tested were of a variety of different types of steel ranging 
from ordinary mild steel to special deep drawing steels and in addition strips of stainless steel were also tested. The width (b) of the strips was $9 \mathrm{~mm}$ and they ranged in thickness (t) from $0.75 \mathrm{~mm}$ to $2.00 \mathrm{~mm}$. Four spacings were used namely, 9, 11, 13, $15 \mathrm{~mm}$ allowing a wide variation in the ratio $t / R$ where $R$ is the average bend radius. The strips were cold bent from flat around a mandrel of roughly $1.5 \mathrm{~mm}$ less than the spacing.

Each specimen was tested under controlled displacement cycling, hysteresis loops being recorded during the test. A wide range of preset displacements were used. The results of immediate interest are the peak load, the energy dissipated per cycle, and the total. number of cycles to fallure. The mode of failure for this mechanism took the form of a localized kinking of the strip followed rapidly by complete transverse fracture. It was observed that before the initiation of kinking the initial semi-circular shape was fairly well maintained even at relatively large displacements (e.g. $2.5 \mathrm{~cm})$.

In all situations involving reversed loading the usual theory of perfectly plastic behaviour does not represent the response with any degree of accuracy. In general the initial yield follows the elastic plastic model but on reversal and on subsequent cycles the well defined yield point disappears and the response curves differ substantially from the elastic plastic idealization. Nevertheless a rigid plastic analysis is of considerable value in identifying relationships. Thus we consider first the plastic analysis of a typical specimen. An upper bound to the yield load is given by assuming a velocity field the simplest of which is to assume that the strip retains its circular shape. The load applied to the centre post of the double strip system does work at a rate $P \dot{\Delta}$ where $\dot{A}$ is the displacement rate. The rate of dissipation of energy $D$ in each strip is given by

$$
D=\int M \dot{K} d s
$$

where $M$ is the moment, $\dot{K}$ the curvature rate and ds the element of length along the strip. The curvature rate is singular; the lengths over which it varies are zero but these lengths move along the bar with speed $\dot{\Delta}$. Writing the integral' in the form

$$
D=\int M \dot{K} d s / d t d t
$$

and noting that $M= \pm M_{O_{1}}$ (defined below), that $\stackrel{\mathrm{K}}{\mathrm{c}}$ changes from 0 to $1 / \mathrm{R}_{\mathrm{R}}$ to 0 , we have

$\mathrm{D}=\frac{\mathrm{ds}}{\mathrm{dt}} \int \mathrm{M} \dot{\mathrm{K}} \mathrm{dt}=\frac{\dot{\Delta}}{2}\left(\mathrm{M}_{\mathrm{O}} \frac{1}{\mathrm{R}}+\left(-\mathrm{M}_{0}\right)\left(-\frac{1}{\mathrm{R}}\right)\right)$

Thus an approximation to the yield load for two U-strips is

$$
\mathrm{P}^{+}=2 \mathrm{M}_{\mathrm{O}} / \mathrm{R}
$$

This result does not take into account the influence of the force $P$ on the yield load moment $M_{O}$ and due to the method of loading such an interaction is possible. The yield condition for combined axial force $P$ and bending moment $M$ on a rectangular beam (see Prager and Hodge (11) is

$$
\left|\mathrm{M} / \mathrm{M}_{\mathrm{O}}\right|+\left(\mathrm{P} / \mathrm{P}_{\mathrm{O}}\right)^{2}=1
$$

where $M$ is the yield moment in the absence of axial 1 oad and $P_{0}$ the yield axial load in the absence of bending. Thus the above result should be replaced by

$$
P=\frac{2 M_{O}}{R}\left(1-\left(\frac{P / 2}{P_{o}}\right)^{2}\right)
$$

or

$$
P=\frac{2 M_{O}}{R}\left(1-\left(\frac{M_{o}}{P_{o} R}\right)^{2}\right)
$$

Since $M_{O}=\frac{1}{4} \sigma_{y} b t^{2}$ and $P_{0}=\sigma_{y} b t$ for a rectangular cross section, where $\sigma_{y}$ is the yield stress in simple tension the correction term

$$
\left(\mathrm{M}_{\mathrm{o}} / \mathrm{P}_{\mathrm{O}}{ }\right)^{2}=\mathrm{t}^{2} / 16 \mathrm{R}^{2}
$$

In the mosc extreme case tested namely $t=2 \mathrm{~mm}$ and $R=5.5 \mathrm{~mm}$ this ratio is less than $1.0 \%$ and the average over all specimens is around $0.3 \%$ so that interaction of this kind need not be taken into account.

The yield load is not a quantity of particular interest in a cyclic test since after a very few cycles no well defined yield point exists. Nevertheless it suggests correlations between quantities which can be useful in the design of devices based on the particular mechanism under study. In the present case the result suggests that the maximum load for two U-strips will be given by a formula $P=\sigma b t^{2} /(2 R)$ where $\sigma$ is an effective cyclic stress. A large number of results have been plotted in Fig. 7 for both mild steel and for stainless steel strips. The results for the various types of mild steel lie on the same straight line indicating the similar yield and hardening properties of these materials. The stainless steel results lie on a much higher straight line. The slopes of these lines indicate stresses, $\sigma$ of $400 \times 10^{6} \mathrm{~N} / \mathrm{M}^{2}(60,000$ p.s.i.) for the mild steel and $760 \times 10^{6} \mathrm{~N} / \mathrm{M}^{2}(114,000$ p.s.i.) for the stainless steels. These stresses may be compared with average yield stresses obtained in simple tension tests on specimens of the strip materials of $274 \times 10^{6}$ $N / M^{2}(40,000$ p.s.i.) for the mild steels and $350 \times 10^{6} \mathrm{~N} / \mathrm{M}^{2}(52,000 \mathrm{p.s.i.})$ for the $0.2 \%$ proof stress of the stainless steels.

The strain which is developed during a test does not depend on the stroke; on the assumption of plane sections in the deformed region and circular curvature it is given by

$$
E_{\max }=t / 2 R
$$

and this ranges from $5.3 \%$ to $17 \%$

Since the object of these devices is to dissipate energy, the energy dissipated per cycle is a result of some importance. This can be estimated from the hysteresis loops recorded during each test. Due to the fairly substantial strains which are developed and the fact that 
68

the strain level is constant but the deforming region moves along the strip the load displacement curve of the device is very rectangular and the enclosed area was found to be consistently $90 \%$ to $94 \%$ of the rectangle based on the peak load. Thus an average value of the energy dissipated per cycle is given by

$$
c \hat{\sigma} b t^{2} s / R
$$

where $c$ is a factor of the range .90 to .94, $\hat{\sigma}$ is the effective cyciic stress and $S$ is the stroke.

The lifetime of an energy absorbing device is naturally of considerable importance and it is useful to identify the factors which contribute to the failure of the device. In the case of the double strip system the quantities which appear to influence the results most strongly are the stroke and the level of maximum strain. It is generally accepted (see e.g. Morrow (12) ) that the 1 ife of a struct. ural element subject to cyclic loading is controlled by the amount of energy dissipated per unit volume of the material. In the case of the U-shaped strips the volume of material involved in the deformation depends on the length of the stroke. When tne half stroke is less than the original bent length i.e. $\pi \mathrm{R}$ the length of deformed material in each strip is just the stroke length itself. When the half stroke exceeds $\pi_{R}$ the length involved is $\left(\frac{S}{Z}+\pi R\right)$. The energy dissipated per unit

volume per cycle, e, is given by

$$
e=c \hat{V} t / 2 R
$$

for $S<2 \pi R$ and

$$
e=c t / 2 R \frac{S}{s+2 \pi R}
$$

\section{for $s<2 \pi_{R}$}

In bending and unbending with maximum strain $t / 2 R$ the work done per unit volume would be $2 \mathrm{c} t / 2 \mathrm{R}$, but without unbending ( $S<2 \pi \mathrm{R}$ ) the deformed portion is loaded only in one direction. In the second case ( $\left.S>2 \pi_{R}\right)$ a portion of the strip of length $s / 2-\pi_{R}$ is subject to bending and unbending. The second result is thus only an average and the dissipation is ctit/2R in the two regions each of length TI $R$ which are deformed only once and $c \hat{\sigma} t / R$ in the central region of length $5 / 2-\pi_{R}$ between these which is loaded twice. The final collapse of the system, generally took the form of the development of a region of highly localized deformation, the formation of a kink on one or both of the strips, followed by rapid transverse rracture thus tending to corroborate this pattern of energy dissipation; for small strokes the rinal fracture occurred in one of the lateral regions and for large strokes in the central region. This suggests that the number of cycles to failure would decrease very rapidly for strokes greater than $2 \pi R$ and would tend to decrease ith increasing strain.

In principle the life of the device should be independent of stroke when the stroke is less than 2 TR. In ract it is found that the 1 ife increases with decreasing stroke even in this range. The rate of decrease of cycles with stroke appears to increase markedly when the. scroke is greater than $\pi \mathrm{R}$ which is probably due to the fact that the deformation tends with cycling to spread from the points at which it is theoretically located and thus involves more material in the doubly loaded region than the above calculation predicts.

The implications of this result for the design of a device are that the stroke should be selected to be not more than $\pi_{R}$ but should not be much less than this value in order to minimize the amount of material which is undeformud during a cycle of loading, and that the strain level be kept to a low enough value to ensure that the specified 1 ife is achieved. A large number of tests at different strain levels using several different stroke to radius ratios were carried out. The results show a certain amount of scatter but generally reflect the trends indicated above. The results have been used to prepare the diagram of cycles against strain and stroke shown in Fig. 8 .

In the course of the test program a number of different approaches were used in an attempt to overcome the problem of kinking of the strip which led to its final collapse. The onset of kinking generally took place several cycles before final collapse but during these terminal cycles the peak load and the shape of the load displacement curve became very unpredictable. A specified peak load and a reliable hysteresis loop are, of course, a prerequisite for a successful working device. To attempt to overcome these difficulties, constraining rollers were used in some tests and rollers with guides in others. The constraining rollers worked satisfactorily giving a somewhat increased peak load, and a longer 1 ife, but required adjustment during the test to maintain contact with the strip whicn tended to increase somewhat in length. This slight increase in length prevented the system with both rollers and guides from working satisfactorily. An alternative to the roller system was to use stainless steel for the strip material. Stainless steel strips gave consistently life times which were longer than the mild steel strips; the work hardening properties of the material appeared to prevent the localization of deformation which produced the kinking in the mild steel.

Although the use of rollers and the use of stainless steel led to an improvement, they are not considered to be useful for the design of a full scale device. The expense and complication of the roller design together with the need to adjust it in operation, are major disadvantages and the expense of the stainless steel in comparison to mild steel is a handicap as also is the fact that for a full scale device the forces required to form the originally straight strip into the required semi-circular shape would be much larger than those needed for mild steel. It appears that simplicity of the mild steel, unrestrained device can be achieved if the strain level and the stroke are kept within the limits required to produce lifetimes in excess of the specified minimum (e.g. 100 cycles). In view of the fairly small structural displacements which will be developed in a building under earthquake loading these may be expected to be in the range 2.5 to $5.0 \mathrm{~cm}$. and the fairly high forces required of the device (e.g. $150,000 \mathrm{~N})$ means it is 1 ikely that the ratio of stroke to radius will be such that life times in the range $100-200$ cycles could be reliably guaranteed with useful values of the plastic strain.

For example, a single strip device required 
to develop a peak load of $25,0001 \mathrm{~b}(112,000 \mathrm{~N})$ might have the following dimensions. We assume that a strain of $10 \%$ is possible and using this we obtain $\mathrm{b}=20 \mathrm{~cm}, \mathrm{t}=2.7 \mathrm{~cm}$ and $\mathrm{R}=13.5 \mathrm{~cm}$, the total width of the device is $\mathrm{s}=19.7 \mathrm{~cm}$ and at a $5 \mathrm{~cm}$ stroke $(\mathrm{s} / \mathrm{R}=0.375)$ it snould develop a minimum of 150 cycles of operation. These dimensions are relatively modest by structural standards.

(b) Test Results on Torsional Energy Absorption

\section{(i) Tests in Pure Torsion}

In an initial series of tests carried out to determine the feasibility of using torsion as a mechanism of absorbing energy bars of square and circular cross section were subjected to cyclic plastic torsion. The bars were twisted in the device shown in Fig. 9. which was loaded in a standard Instron testing machine. The machine was set to impose displacement controlled cycles, the angle of rotation of the lever being kept constant for each test and the maximum shear strain being varied by varying the length of the test bar.

In the absence of adequate strain gauge equipment to record the strains at the plastic strain level used in the tests the maximum plastic strain in the square bars was estimated by the use of the formula

$$
\mathscr{\gamma}_{\max }=1.35 \frac{\mathrm{a} y}{2}
$$

where $a=$ width and thickness of bar " clear length

- Pangle of rotation

The nominal maximum strains recorded on the diagrams are computed from this formula. The range of strain covered in these tests was from $3.75 \%$ to $13.2 \%$. Three materials were used in the tests, as follows :

(a) Cold rolled mild steel as delivered (severely cold worked)

(b) Cold-rolled mild steel annealed

(c) Hot rolled mild steel from $\frac{1}{2}{ }^{n}, 1 "$ and $2 \frac{1}{2}$ " sizes.

In each test the bar was cycled at the maximum rate of the Instron machine, (equivalent to 1 cycle per minute in the case of a 5 inch lever and $a \pm 5 \mathrm{~cm}$ stroke). A typical set of results are shown in Fig. 10. For each test a few complete torque twist loops were drawn to determine the initial hardening behaviour then the displacement axis was replaced by a time axis and a plot of maximum torque as a function of cycles was obtained.

Reduced torque vs cycle curves for several materials are shown in Fig. 11. The cold rolled material shows an exponential decrease in maximum torque beginning from the first cycle. The hot rolled material from the $\frac{1}{2} n$ size work hardens during the first few cycles then shows a linear decrease in peak torque with cycles. The hot rolled material from the $2 \frac{1}{2} "$ size work hardens somewhat less, exhibits a flat portion and then a linear decay.

A few similar tests were carried out on bars of circular section. To facilitate gripping these specimens they were machined rrom square stock, a smooth transition region being provided. These bars were tested in both the annealed and unannealed states and in all cases failed due to transverse cracking at the transition region. The unannealed bars failed during the first reversal and the annealed after several reversals. It is not believed that these tests constitute an adequate test of the application of bars of circular cross section. However, the difficulty of providing grips which do not introduce stress concentration problems remains and is a substantial factor in favour of square bars.

There are several observations of a general nature which we should mention here. All materials tested exhibited on first yield a flat portion on the torque twist curve followed by a linear hardening portion. On reversal the torque twist curve does not exhibit a flat portion and is in fact curved over the entire region of reversed torque. The deviation from elastic behaviour begins in general before the torque changes sign. The torque twist loops rapidly reach a steady state shape which is very different from the elastic perfectly plastic idealization. The area within a typical loop was estimated from a number of examples to be in the range $60-65 \%$ that of the rectangle defined by the extremities of the loops. Further it is clear from this set of results that cyclic loading is producing less hardening than monotonic loading, and is more damaging to the material. For example, the cold rolled material in the unannealed condition could be twisted unidirectionally to a twist of about one revolution per inch on a $\frac{1}{4}$ " square or circular bar while continuing to harden. With cyclic loading on the other hand, for a maximum rotation of $+22 \frac{10}{2}$ the square bar progressively softenēd and the circular bar failed during the first reversal. A comparison of unidirectional as opposed to cyclic loading for hot rolled mild steel is shown in Fig. 12 in which curves of torque versus cumulative plastic twist are shown. There the hardening during the first few cycles is particularly severe, but is not comparable to that for unidirectional loading. It was also noted that even at the very substantial twists there was no apparent change in length of the bar. Also noted during the unidirectional tests was the fact that there were no apparent cracks along the length of the bar. However, reversal from any substantial level of twist produced immediately a pattern of longitudinal cracking.

The pattern of failure in the cyclic torsion of square bars is different from that experienced by the U-shaped strips. The peak torque achieved at the end of each stroke remains constant for a number of cycles which may range from less than 10 for high strains to more than 100 for low strains. A progressive drop in the peak torque follows, the rate of the decay depending on the strain, and associated with this is a pattern of longitudinal cracks extending the full length of the bar. No precise point of failure can be determined as the bar continues to dissipate energy at a progressively decreasing rate as the torque falls off. This pattern of progressive failure is felt to be a consid. erable advantage of torsion in square bars as a mechanism of energy absorption in that at all times the integrity of the bar is maintained, and the collapse of the bar occurs in a controlled non-catastrophic manner.

Since the primary purpose of the devices will be to absorb energy it is useful to 
70

evaluate the energy density dissipated per cycle. Given that the area of the loop is around $\frac{2}{3}$ of the rectangular area defined by the peak value of the torque $T$, the energy density $e$ is given by

$$
e=c 4 T / a^{2}
$$

where $c$ is a constant around $\frac{2}{3}$.

When, for example, a torque of around $19501 \mathrm{~b}$. in. is developed in a $1^{\text {w }} 1$ ength of $\frac{1}{2}$ square bar at an angle of rotation of $\varphi=\operatorname{arc}$ sin $(1 / 2.54)$ the energy density per cycle is $75001 \mathrm{~b}$ in $/ \operatorname{in}^{3}\left(50 \times 10^{6} \mathrm{~N} / \mathrm{M}^{2}\right)$. The beginning of the decay in peak torque for $\frac{1}{2}$ " square bars cut from the $2 \frac{1}{2}$ size hot rolled mild steel is at 40 cycles with a peak torque around 1950 $1 \mathrm{~b}$. in ( 213 NM) for the 1 " long bar, at 120 cycles at 1800 1b.in (196 NM) for the 2" bar and at 220 cycles at 1600 lb.in ( $175 \mathrm{NM})$ for the 3" bar. The cumulative energy density dissipation is $3.4 \times 105,4.5 \times 105$ and 4.7 $\mathrm{x} 1051 \mathrm{~b} . \mathrm{in} / \mathrm{in}^{3}\left(2.3,3.1,3.2 \times 109^{\mathrm{N}} / \mathrm{M}^{2}\right)$ for 1", 2", 3" bars respectively. Roughly then the initiation of peak 1 oa d decay appears to be around $4105 \mathrm{Ib}$. in $/$ in $^{3}\left(2.8 \mathrm{x} 109 \mathrm{~N} / \mathrm{M}^{2}\right)$ accumulated dissipation for this material. This does not of course mean that the material cannot dissipate more energy, the linear decrease in peak torque with cycles implies that the total energy dissipation capacity of the material is of the order of $9 \times 105$ to 13 $x 105 \mathrm{lb}$.in/in $3.7 \times 109$ to $\left.9.0 \times 10^{9} \mathrm{~N} / \mathrm{M}^{2}\right)$.

The resulus of this test series indicate that the hot rolled mild steel in the $2 \frac{1}{2}$ " size has highly favourable behaviour from the point of view of an energy absorbing device in a structural system, if used at strain ranges around $4 \%$. At this range, cyclic hardening is small and achieved within the first few cycles, and a range of 200-300 cycles of uniform peak load follows with a substantial reserve of strength left. On the basis of these results the design of a suitable device incorporating torsion as the primary mechanism was explored. It was found that a substantial simplification of design could be achieved if the load was applied to the torsion bar in such a way as to develop flexure in addition to torsion. To determine that the energy absorption properties wore not adversely affected by the addition of flexure the following tests were carried out.

\section{(ii) Combined Torsion and Bending}

As pointed out in the previous section the design of a torsional energy absorbing device can be greatly simplified if it is possible to apply the torque through a single lever at the center of the bar.

The apparatus used to load the bars in combined bending and torsion is shown in Fig. 13. Although a certain amount of vertical deflection occurs under the mid-point of the bar and this has the effect of reducing the total angle of twist applied to the bar the deflection at the end of the lever arm was taken to be the specified quantity in the series of tests. This vertical displacement has no effect on the torque at which yield is initiated but since it reduces the maximum shear strain to which the bar is subject it tends to reduce the maximum torque in the bar. This is particularly noticeable in bars with long clear lengths. One way of minimizing this variation in the maximum shear strain due to bending is to maintain the length $\mathcal{L}$ and vary the lever arm $s$ while maintaining the same nominal angle of rotation. The results of such tests are shown in Fig. 14 (a) and 14 (b). Fig. $14(\mathrm{a})$ we plot torque against cycles for $\frac{1}{4}$ square bars of annealed bright mild steel with $\boldsymbol{\ell}=2 "$ ", which corresponds to a nominal shear strain of $3.75 \%$, and $S=1^{\prime \prime}, 1 \frac{1}{2} "$ and $2 "$ corresponding to $\boldsymbol{L} / \mathrm{s}=2,1.33,1.00$. There is very 1 ittle difference between the $1 \frac{1}{2} "$ and 2 " curves but the 1" lever curve shows a very rapid drop in torque after 300 cycles. In Fig. 14 (b) the same results are plotted for clear lengths of 1 ", corresponding to a nominal $7.5 \%$ strain. Here the curves do not differ very much one from the other. The values of $/ / 5$ are 1.0 , $0.67,0.5$. The results of a series of tests on $\frac{1}{2}$ " square hot rolled mild steel bars is shown in Fig. 15. In this case the lever arm was maintained constant at $2 "$ and the clear length increased in steps from 1" through 2", 3" to $4 \frac{3}{4} \%$. As noted in the previous section there is evidence that this steel is inferior in its cyclic plastic fatigue resistance to the annealed bright mild steel, (comparison of the case $\boldsymbol{\ell}=2 "$ and $s=2 "$ with the equivalent case $\boldsymbol{\ell}=1^{\prime \prime}, S=1^{\prime \prime}$ for the $\frac{1}{4}$ " square bars shows that the decay is more rapid). However, the failure mode pattern is the same. For $\ell / s=$ 1.50 and less, there is a gradual decay associated with longitudinal cracking of the bar; for $\ell / s=2.00$ and above, the torque remains constant followed by a rapid drop associated with transverse cracking of the bar. In repeated tests the decay curve when longitudinal cracking occurs is repeatable, whereas when transverse cracking occurs the number of cycles at which the rapid collapse occurs varies widely from test to test.

A curious and somewhat unexpected phenomenon associated with the combined torsion and bending is a lateral displacement of the center of the bar toward the loaded side. This appears to be due to the interaction of the rotation of the center portion of the bar and the applied force. The machine applies a vertical force so that when the lever is near the lower extent of the travel and moving downward the bar is yielding and experiences a force component which for the central portion at least is in the originally horizontal direction. When the lever is moving up and near the top there is again a force component in the originally horizontal direction. The plastic part of the downward displacement produced by the downward force is cancelled by that produced by the upward force. However, the displacements produced by the force components in the originally horizontal direction are additive and a cumulative lateral drift of the center of the bar results.

Measurements of the lateral drift were taken for a $\frac{1}{4}$ square annealed bars using 1" and 2" clear lengths and levers of 1", $1 \frac{1}{2}$ ", $2 *$ and 5". A few tests on circular bars were also carried out. The results indicate that the drift is in fairly good correlation with proportionality with $\boldsymbol{l} / \mathrm{s}$. The circular bar gave values of drift that exceeded those for the square bars of the same $\boldsymbol{l}$ and $s$. A surprising and unexplained result is that the drift does not increase linearly with cycles as might be expected but appears to be proportional to the square root of the number of cycles. 
Following the tests involving torsion of square bars which were described in the previous two sections, 3 (ii) (a) and (b), a number of scale model devices were designed based on the results of these tests. During the testing of the scale model devices it became clear that gripping of the square bar in the device constituted a more substantial problem than it had done in the preliminary tests. The difficulties which arose and the several approaches to their solution will be outlined in the following section. One approach was to consider the use of a torsion bar of rectangular cross section and to this end a series of tests on combined torsion and bending of rectangular bars was undertaken.

The apparatus, (see Fig. 16) used in the torsion testing of rectangular bars had been developed for 1" square bars and using packing pieces of various thicknesses in the grips it was possible to test bars of 1 " width and varying thickness. It was a feature of this apparatus that the bar could be loaded with the wider face either horizontal or vertical. Thus two bars each of cross sections 11 x $\frac{1}{2} "(2.54$

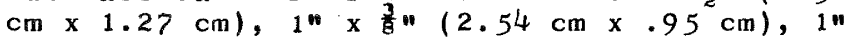
$x \frac{1}{4} "(2.54 \mathrm{~cm} \times .64 \mathrm{~cm})$ were tested, one of each pair having the wider face horizontal and the other having it vertical. The lever arm, angle of rotation and bar length were the same in each test. A summary of the test results together with those for a square bar of 1" $(2.54 \mathrm{~cm})$ side of the same length, lever arm and maximum angle of rotation, is given in Table $\mathrm{r}$.

There are two points which are immediately apparent from this table. The first is that the rate of decay of the rectangular bars is less than that of the square bar, and is increasingly less as the bar width to thickness increases. The second is that there are no outstanding differences between bars in the horizontal or vertical position. The peak loads and decay are the same within the rather large variability common in these tests. This latter result is somewhat unexpected since the elastic bending stiffness and the plastic yield moment when the wider face is horizontal are both much less than when it is vertical. The explanation for this result appears to be that the bending response, both elastic and plastic, is of negligible importance in the case of such large torsional displacements for these ratios of length to lever a rm.

To gain an insight into the improved decay behaviour of the rectangular bars, we consider the perfectly-plastic analysis of the torsional response. The torque $T$ in the case of a rigid perfectly-plastic material is given by, (13)

$$
T=\tau_{y}\left\{\frac{b^{3}}{3}+(a-b) \frac{b^{2}}{2}\right\}
$$

where $a$ is the longer side and $b$ the smaller side of the rectangular cross section, and is the yield stress in shear. We assume that the same formula will apply with $\tau_{y}$ replaced by an effective stress dependent on the strain. The energy dissipated per cycle per unit volume of material is thus:

$$
\mathrm{e}=\frac{4 \mathrm{~T} \varphi}{\ell \mathrm{ab}}=\frac{4 \hat{\tau}}{\ell} \frac{3 \mathrm{ab}-\mathrm{b}^{2}}{6 \mathrm{a}} \varphi
$$

$$
\mathrm{e}_{\mathrm{s}}=\frac{4 I}{\mathrm{l}} \frac{\mathrm{a}}{3} \boldsymbol{\varphi}
$$

thus

$$
e_{s}=\frac{3 a b-b^{2}}{2 a^{2}}
$$

For the 1" $x \frac{1}{2} ", 1^{\prime \prime} \times \frac{3}{8} ", 1^{\prime \prime} x \frac{1}{4} "$ bars this ratio is $0.625,0.49,0.41$ respectively. If we accept that the primary factor in the damage of the system is the energy dissipated per unit volume of the material, the explanation for the reduction in the decay of the peak load is clear. The rectangular bar is less efficient in its energy absorption capacity than the square bar and becomes increasingly less efficient as the ratio of the long side to the short side increases. Thus if a certain energy absorption per cycle is specified it is necessary to use more material if rectangular bars are used. On the other hand, the amount of active material in the energy-absorbing devices is not great and increasing it by a factor or two, for example, may in most circumstances be an acceptable penalty to pay for the increased ease of gripping the bar.

\section{(c) Tests on Flexural Energy Absorption}

An obvious application of the energy absorbing device approach is to use them to replace the energy absorption which takes place in a multi-storey frame at the beam column connections by that from devices located in a system of diagonal bracing. A design in which the frame is required to resist vertical and wind load and the bracing provides the energy absorption capacity could lead to a lighter and less expensive structure if suitable energy absorbers were available. The bracing need not be over the entire frame. A computer study of the effect of yielding of bracing in multistorey frames was carried out by Hanson and Fan (14). The basic structure under study was a single-bay multi-storey rigid-jointed frame with a variety of bracing configurations ranging from fully braced, through two configurations of partial bracing, to fully unbraced. They found that early yielding in the bracing resulted in energy dissipation requirements for the girders significantly below those needed for the unbraced frames. In addition the energy dissipation appeared to be more uniformly distributed throughout the structure.

The difficulty of designing such a device 1 ies in the fact that it must be able to $f$ it within the thickness of a wall panel. The torsional device by its nature is three dimensional in that the load is applied in one plane while the active element, the torsion bar, 1 ies in another plane. However, flexure is an essentially planar mechanism and the device developed for this application has been based on this principle.

The anticipated working form of the device has been shown in Fig. 1 (c). A simplified form of the device was used to study the response of the basic mechanism, to determine its energy absorbing capacity and fatigue characteristics. This is shown in Fig. 17. The energy-absorbing components are the short beams of clear span, each side, $\ell$, depth $t$, and 
72

width b. These beams are located in such a way that they can be deformed to substantial plastic strains without the development of forces in the originally axial direction. The device is subject to a cyclic displacement with stroke $S$. The maximum central displacement of one beam, assuming symmetric response, is $\mathrm{S} / \mathrm{H}^{\text {. The }} \mathrm{dis}$ placements used in the tests are of the order of the thickness of the beams. The maximum angle of the deformed beams middle surface is of the order of $30^{\circ}$ and thus an axial force in the beam is developed, the magnitude of this force is nevertheless sufficiently small to have a negligible effect on the bending response.

A series of devices of the type shown in Fig. 17 were tested under displacement-controlled cyclic loading. It was found from an initial series of tests that the life time of the beams could be considerably enhanced by the use of a system of restraining guides. The guides are clearly seen as the short cantilevers with rounded ends in Fig. 17. They were short lengths of mild steel of the same width and somewhat thinner than the beams and struck out a distance of half their width from the clamping edge. These guides had the effect of distributing the deformation in a more uniform manner near the clamped ends. The criterion which was used to determine the optimum dimensions of the guides was the point on the beam at which the final crack developed. If this point lay directly under the clamping edge the guide was considered to be insufficiently rigid and if at the edge of the guides these were taken to be too rigid. The results quoted in what follows pertain to those tests in which guides adjusted according to the above criterion were used. A typical hysteresis loop is shown in Fig. 18. These loops are quite different from those obtained for the U-shaped strips or for the torsional device. On first loading a well marked yield point is noted but it is followed by rapid linear hardening. This rapid linear hardening has the effect that the peak load and the energy absorption per cycle are strongly dependent on the stroke. The use of the guides makes it difficult to accurately assess the maximum strain level reached in the test but maximum strain level reached in the test but be used in interpret the results. Plots of peak $10 a d$ as a function of $5 t / 2$ are shown in Fig. 19. The straight line drawn through the points indicates that for the purpose of design the peak load can be estimated from

$\begin{aligned} P & =\frac{b t^{2}}{2}\left(1+\omega^{s t} / 2\right) \\ \text { with } \sigma & =320 \times 10^{6} \mathrm{~N} / \mathrm{M}^{2} \text { and } \alpha=20\end{aligned}$

The yield load predicted by a rigid plastic theory for this situation is

$$
P \equiv \sigma_{y} b t^{2} / \mathscr{d}
$$

We note that the projection of the line through the results back to the st/ $\mathbb{2}^{2}=0$ axis intercepts at $320 \times 10^{6} \mathrm{~N} / \mathrm{M}^{2}$ which compares with a yield stress of $314 \times 10^{6} \mathrm{~N} / \mathrm{M}^{2}$ obtained by uniaxial tension tests on this material.

In each of the flexural tests the peak load was achieved at around the second cycle and maintained constant until one or two cycles before failure which was rapid and due to a transverse crack across one of the beams at one of the four points of maximum moment. There appears to be considerable scatter in the results but the trend appears to be that the lifetime reduces rapidly with increasing stroke. Table II shows a summary of the results. The interesting conclusion is that, in terms of total energy dissipation per unit volume during the lifetime of the system, the short span beams are superior. The explanation for this may be the fact that for a short beam $(t / /<10)$ the thickness of the beam and the presence of the guides tends to spread the plastic deformation more uniformly along the length of the beam, thus using the material with greater efficiency. In an actual device it would be an advantage to keep the elastic deformations of the device to as low a value as possible which is compatible with the other requirements of the system, and since the alastic deformations will increase with increasing slenderness of the beams, this is another factor in favour of using short beams in a device of this type.

For example, a peak load of $135,000 \mathrm{~N}$ could be developed at a displacement of $2.5 \mathrm{~cm}$ by a device with 3 beams top and bottom, each beam having a width of $5 \mathrm{~cm}$, depth $1 \mathrm{~cm}$ and clear length $8 \mathrm{~cm}$ each side. The overall width of this device would be roughly $30 \mathrm{~cm}$ and thickness $15 \mathrm{~cm}$.

It is clear from the test results that this mechanism is not so efficient in energy absorption nor so fatigue resistent as is the torsion of square or rectangular bars, but its advantage is that it can be conveniently located and that it can be readily replaced in the event of earthquake damage.

\section{CONTINUING RESEARCH}

The most important area of continuing research on this approach to earthquake-resistant design is the development of full scale devices which will develop energy-absorption capacities of the order of magnitude required for actual structural systems. A certain amount of work along these 1 ines has already been carried out with a view to providing a torsional device for the piers of the reinforced concrete bridge described in section 2. The general form of the device is shown in Fig. 1 (b) and a number of models which used $1^{\text {* }}$ square torsion bars were constructed and tested. The testing of these models brought to light a number of problems which were not apparent from the test series on the basic mechanism. Details of the development work needed to overcome these problems will be given in a later report.

Briefly the major problems arose out of the transmission of the forces from the levers into the torsion bar. To simplify the construction technique, the square holes in the levers were roughly cut to shape and the levers welded to the bar by fillet welds on both sides. This meant that the weld was used to transmit the torque into the bar and it was found that the device failed at a lower number of cycles than predicted by the basic tests due to a transverse cracking at the welds. To attempt to alleviate this the entire system was heat treated after welding but no improvement was achieved. A further approach was to machine the 1" square bar to $\frac{7}{8}$ square between levers and 
weld the levers again on both sides to the 1" square portion. Again transverse failure with a lower number of cycles than predicted occurred.

A satisfactory system was finally achieved by machining $V$-notches in the levers and bolting them to the bars using high tensile bolts. In this approach the forces are transmitted to the bar through surface contact pressures. In order to keep the contact pressure below the yield point of the material fairly thick levers are required or, alternatively, the cross-sect ion of the bar may be shaped down as before to reduce the moment to be transmitted. Both of these approaches were used and worked.

However an alternative approach which was found to lead to a simpler form of device was to use a rectangular bar as the torsional element. In this case the bar produces, for the same surface area per unit length, a much smaller moment than the square bar and thus the gripping pressures are less critical. The final device is shown in Fig. 20. It will be noted that there are two central levers. Using this the welding can be confined to the outside of the outside levers and to the inside of the inside levers. The moment is transmitted into the bar through contact between the machined surfaces of the slots in the levers, the welds being used only to maintain the levers in place on the bar. This device using a 2 " $x$ 竞" bar developed a force of 2 tons $(20,000 \mathrm{~N})$ with a displacement of $1 \mathrm{~cm}$, developed an energy
absorption per unit vol of $11.6 \times 10^{6} \mathrm{~N} / \mathrm{M}^{2}$ per cycle and maintained this for 200 cycles with a subsequent very gradual decay. At 500 cycles the peak load had reduced to $80 \%$ of the maximum. Accompanying this decay were the predicted pattern of longitudinal cracks. The device is thus entirely satisfactory and on scaling up by a factor of 2.5 should provide the requirements for the railway bridge. Such a full scale model is under development.

Full scale devices for using the other mechanisms are also under development and it is anticipated that it will be possible to test devices by subjecting them to the time history of displacement that they might be called upon to undergo in an earthquake attack. The testing of the devices at the earthquake frequencies is considered to be a matter of priority for future research in this project.

\section{ACKNOWLEDGEMENT}

The authors wish to acknowledge the assistance of D.E. Baguley of P.E.L. Mechanical Engineering section in the use of the test equipment and of H. B. Foster of the P.E.L. Photography section for the photographs used in this report.

\section{REFERENCES}

1. N. M. Newmark, "Current Trends in the Seismic Analysis and Design of High Rise Structures", in Earthquake Engineering, edited by $R$. L. Weige1, Prentice Hall, 1970.

2. J. A. Blume, "structural Dynamics in Earthquake Resistant Design", Trans. A.S.C.E., Vol. 125, pp. 1088-1139, 1960.

3. G. W. Housner, "Limit Design of structures to Resist Earthquakes", Procs. 1st World Conference on Earthquake Engineering, Berkeley, Ca1ifornia, 1956 , pp. 5, 1-5, 13 .
4. E. P. Popov, "Low Cycle Fatigue of Stee Beam to Column Connections", Procs. of the International Symposium on the Effects of Repeated Loadings of Materials and Structures, Vol. VI, RILEM = Inst. Ing., Mexico, 1966

5. E. P. Popov and R. B. Pinkney, "Reliability of Steel Beam-to-Column Connections Under Cyclic Loading", Procs. 4 th World Conference on Earthquake Engineering, Vol. II, Chile, 1969, pp B-3, 15-30.

6. B. Bresler and V. Bertero, "Behaviour of Reinforced Concrete Under Repeated Load", Journal of the Structural Division, A.S.C.E., ST 6, 1968 .

7. J. A. Blume, "Design of EarthquakeResistant poured-in-Place concrete Structures", in Earthquake Engineering, edited by R. L. Wiegel, Prentice-Hall Inc. 1970 .

8. Kiyoshi Muto, "Earthquake Resistant Design of 36-storied Kasumigaseki Building", Procs. 4 th World Conference Earthquake Engineering, Vol. III, Chile 1969, pp. $\mathrm{J}-4,16-33$.

9. J. L. Beck and R. I. Skinner, "The Seismic Response of a Proposed Reinforced Concrete Railway Viaduct", Tech. Rpt No. 369, Physics and Engineering Laboratory, D.S.I.R., 1972.

10. R. Shepherd and R. E. McConnel, "Seismic Response Predictions of a Bridge Pier", Proceedings A.S.C.E., 98, EM 3, June 1972 , $609-627$.

11. W. Prager ana P. G. Hodge, "The Theory of Perfectly Plastic Solids", John Wiley \& Sons Inc., 1956.

12. J. D. Morrow, "Cyclic Plastic Strain Energy and Fatigue of Metals", in Internal Frict ion, Damping and Cyclic Plasticity ASTM STP 31781965.

13. A. Nadia, "Theory of Flow and Fracture of Solids", McGraw-Hi11, 1950.

14. R. D. Hanson and W. R. S. Fan, "The Effect of Minimum Cross Bracing on the Inelastic Response of Multi-Storey Buildings", Procs. 4 th World Conference Earthquake Engineering, Chile, 1969 pp. A-4, 15-30. 
TABLE I

TORSION OF RECTANGULAR BARS

Al1 bars H.R.M.S. Lever arm $2 \frac{3}{4} "$, Stroke $4 \mathrm{~cm}$

\begin{tabular}{|c|c|c|c|c|c|}
\hline Test & $\begin{array}{c}\text { Bar } \\
\text { Dimensions }\end{array}$ & $\begin{array}{l}\text { Peak Load } \\
\text { kg }\end{array}$ & $\begin{array}{l}\text { Energy/cycle } \\
\text { Joules }\end{array}$ & $\frac{\frac{\text { Energy }}{\mathrm{Vol} 2}}{\mathrm{~N} / \mathrm{M}^{2}}$ & $\begin{array}{l}\text { Decay } \\
\frac{\text { Po-Pn }}{\text { Po }} / 100 \text { cycles }\end{array}$ \\
\hline 720 & $2\left(1 " 10 \times 1 " x \quad 2 \frac{1}{8} "\right)$ & 4300 & 2130 & $30 \cdot 5$ & .235 \\
\hline 721 & $2\left(1 "{ }_{V} x \quad \frac{1}{2} " x \quad 2 \frac{1}{8} "\right)$ & 1360 & 663 & 19.0 & . 19 \\
\hline 726 & $2\left(1 "{ }_{H} x \quad \frac{1}{2} " x \quad 2 \frac{1}{8} "\right)$ & 1360 & 716 & 20.4 & .195 \\
\hline 722 & $2\left(1 " \mathrm{~V} \times \frac{3}{8} n \times 2 \frac{1}{8} "\right)$ & 790 & 392 & 17.0 & .10 \\
\hline 723 & $2\left(1 "{ }_{\mathrm{H}} \mathrm{x} \quad \frac{3}{8} " \quad \mathrm{x} \quad 2 \frac{1}{8} "\right)$ & 800 & 392 & 17.0 & .12 \\
\hline 724 & $2\left(1 "{ }_{V} \mathrm{X} \quad \frac{1}{4} " \quad x \quad 2 \frac{1}{8} "\right)$ & 335 & 152 & 8.7 & .03 \\
\hline 725 & $2\left(1 "{ }_{H} x \quad \frac{1}{4} " \quad x \quad 2 \frac{1}{8} "\right)$ & 358 & 167 & 9.5 & .00 \\
\hline
\end{tabular}


TABLE II

SUMMARY OF TEST RESULTS ON FLEXURAL ENERGY ABSORPTION

\begin{tabular}{|c|c|c|c|c|c|c|c|c|c|}
\hline & $\begin{array}{l}\text { Span } \\
\text { in }\end{array}$ & $\begin{array}{l}\text { Stroke } \\
\mathrm{cm}\end{array}$ & $\begin{array}{c}\text { Peak Load } \\
\text { kg }\end{array}$ & $\begin{array}{l}\text { En/cycle } \\
\text { Joules }\end{array}$ & $\begin{array}{c}\mathrm{En} / \mathrm{vol} / \mathrm{cycle} \\
10^{6} \mathrm{~N} / \mathrm{M}^{2}\end{array}$ & $\begin{array}{l}\text { Cycles } \\
1 \mathrm{ife}\end{array}$ & $\begin{array}{l}\text { Cumul. } \\
\text { Ener. Abs }\end{array}$ & $\begin{array}{l}\mathrm{P} 1 / \mathrm{b} t^{2} \\
\mathrm{~N} / \mathrm{M}^{2} \times 10^{6}\end{array}$ & $\frac{100 \mathrm{st}}{\boldsymbol{L}^{2}}$ \\
\hline 805 & 4 & 4 & 490 & 257 & 3.9 & 300 & 1170 & 480 & 2.46 \\
\hline 806 & 4 & 6 & 580 & 465 & 7.1 & 125 & 890 & 570 & 3.70 \\
\hline 803 & 3 & 3 & 725 & 223 & 4.5 & 255 & 1150 & 530 & 3.28 \\
\hline 802 & 3 & 4 & 880 & 357 & 7.2 & 135 & 970 & 647 & 4.36 \\
\hline 801 & 3 & 6 & 1050 & 645 & 13.1 & 55 & 720 & 770 & 6.56 \\
\hline 807 & 2 & 3 & 1550 & 380 & 11.5 & 142 & 1630 & 760 & 7.4 \\
\hline 808 & 2 & 4 & 1850 & 710 & 21.5 & 72 & 1550 & 905 & 9.80 \\
\hline
\end{tabular}




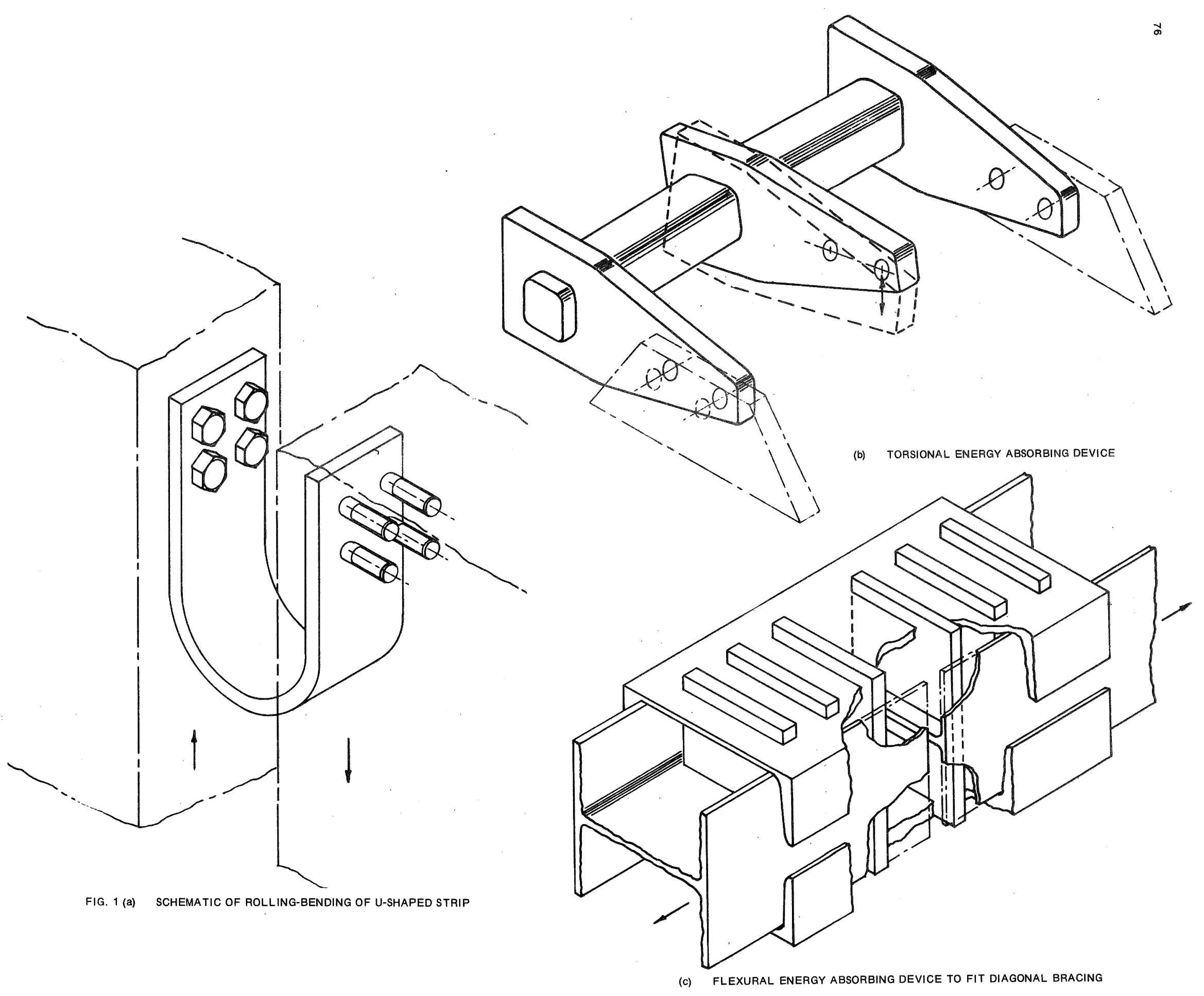



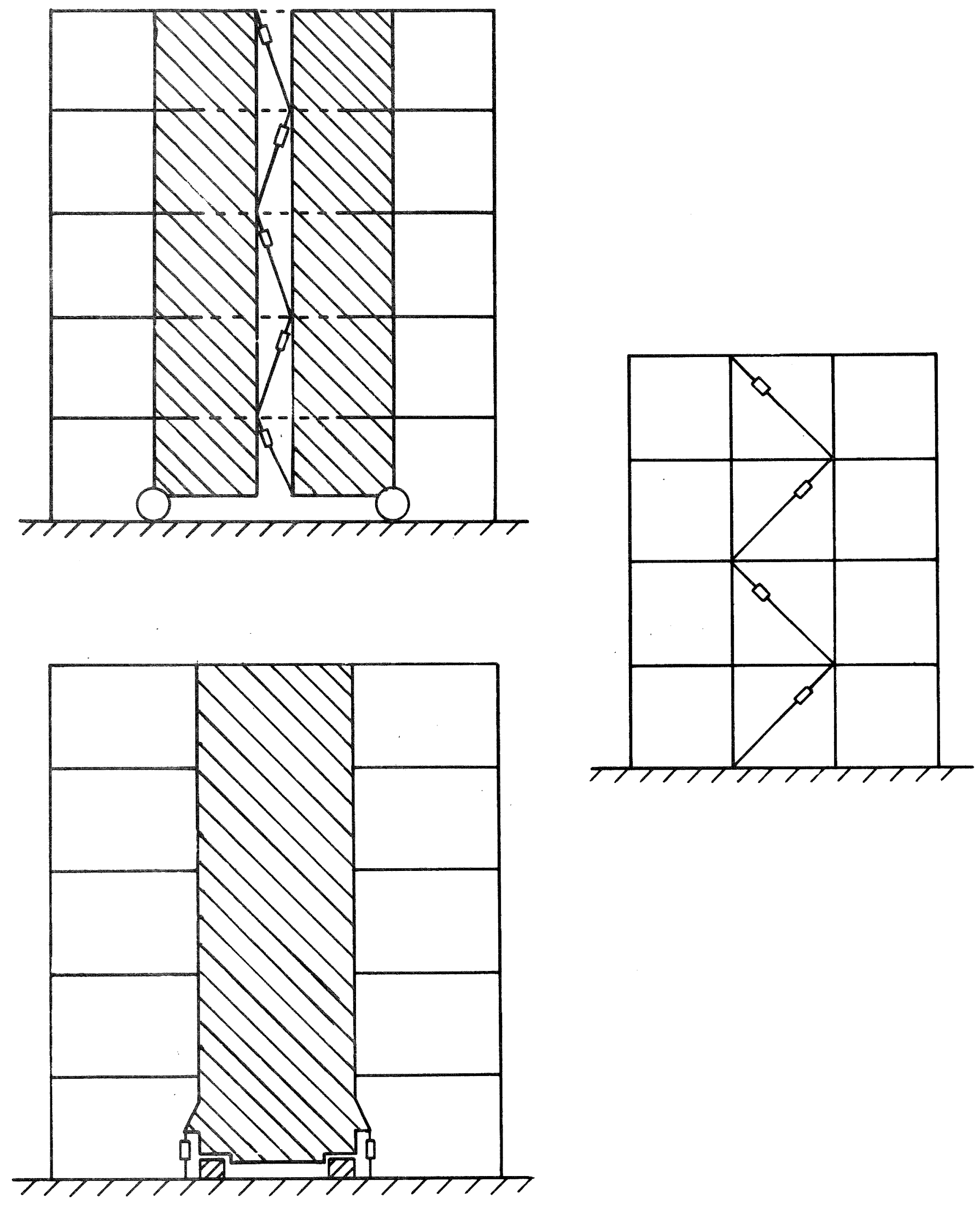

FIG.2 

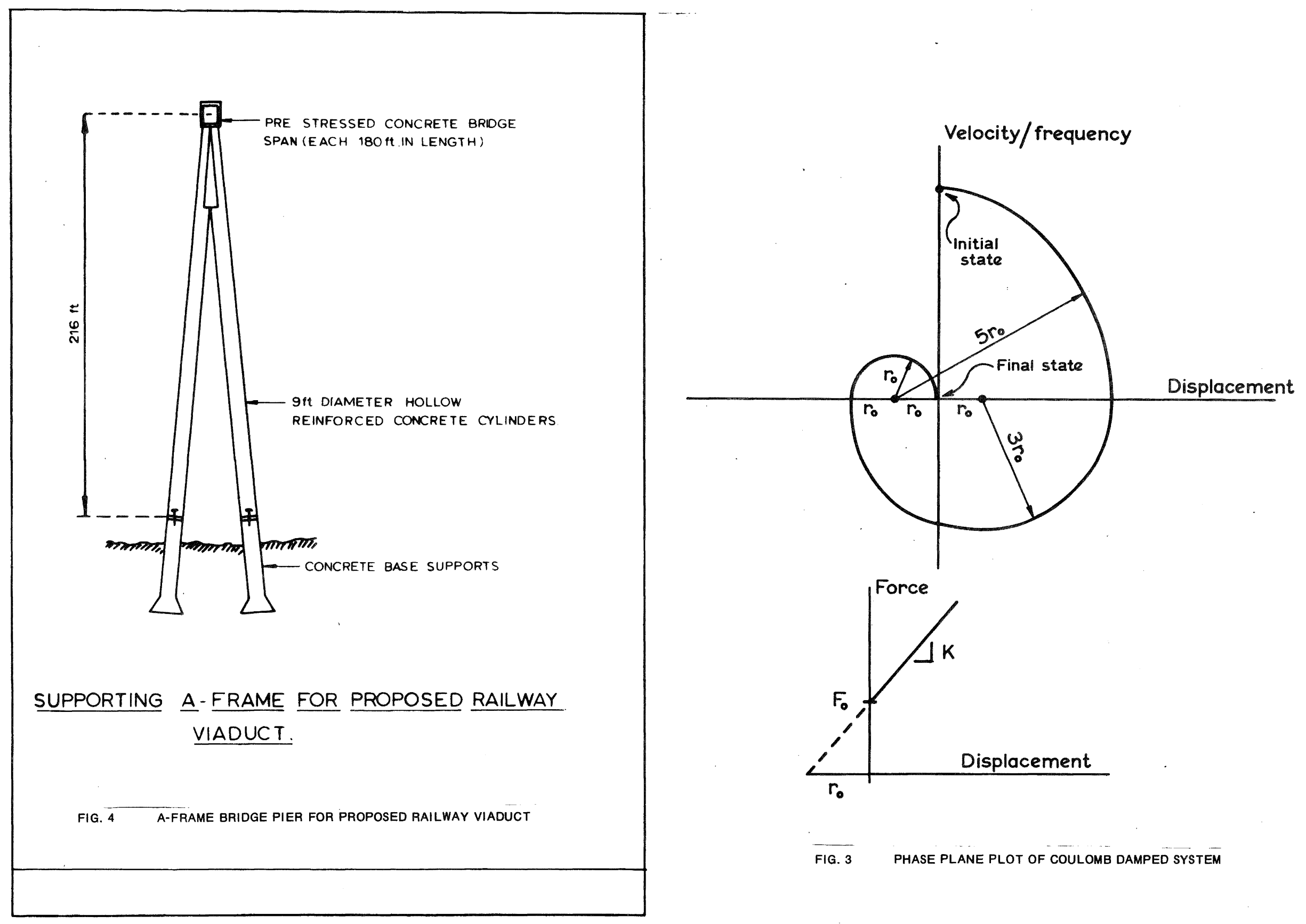

FIG. 3 PHASE PLANE PLOT OF COULOMB DAMPED SYSTEM 
80 $\mathrm{kg}$
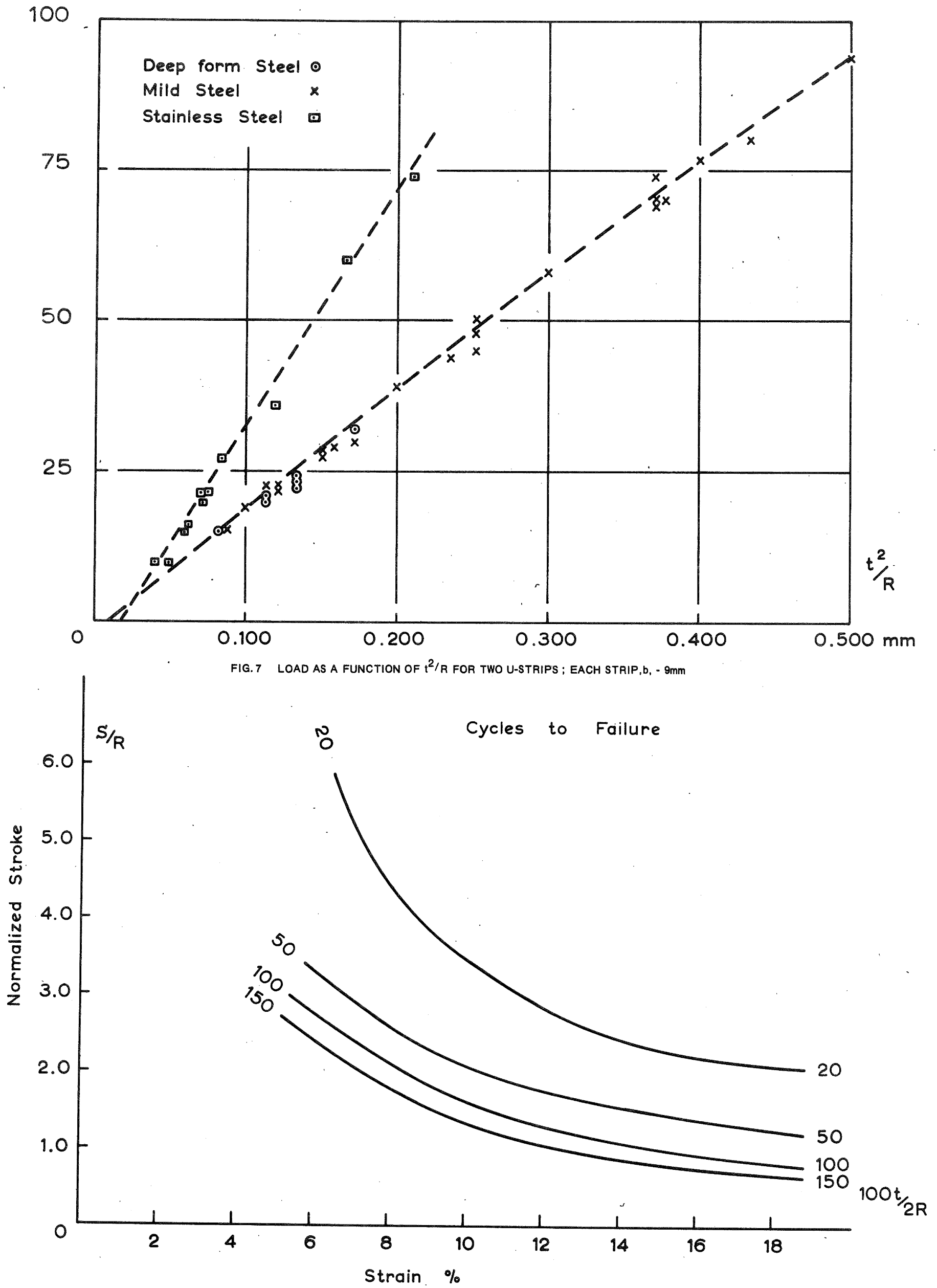

FIG. 8 CURVES OF LIFE TIME OF DOUBLE STRIP TEST APPARATUS 


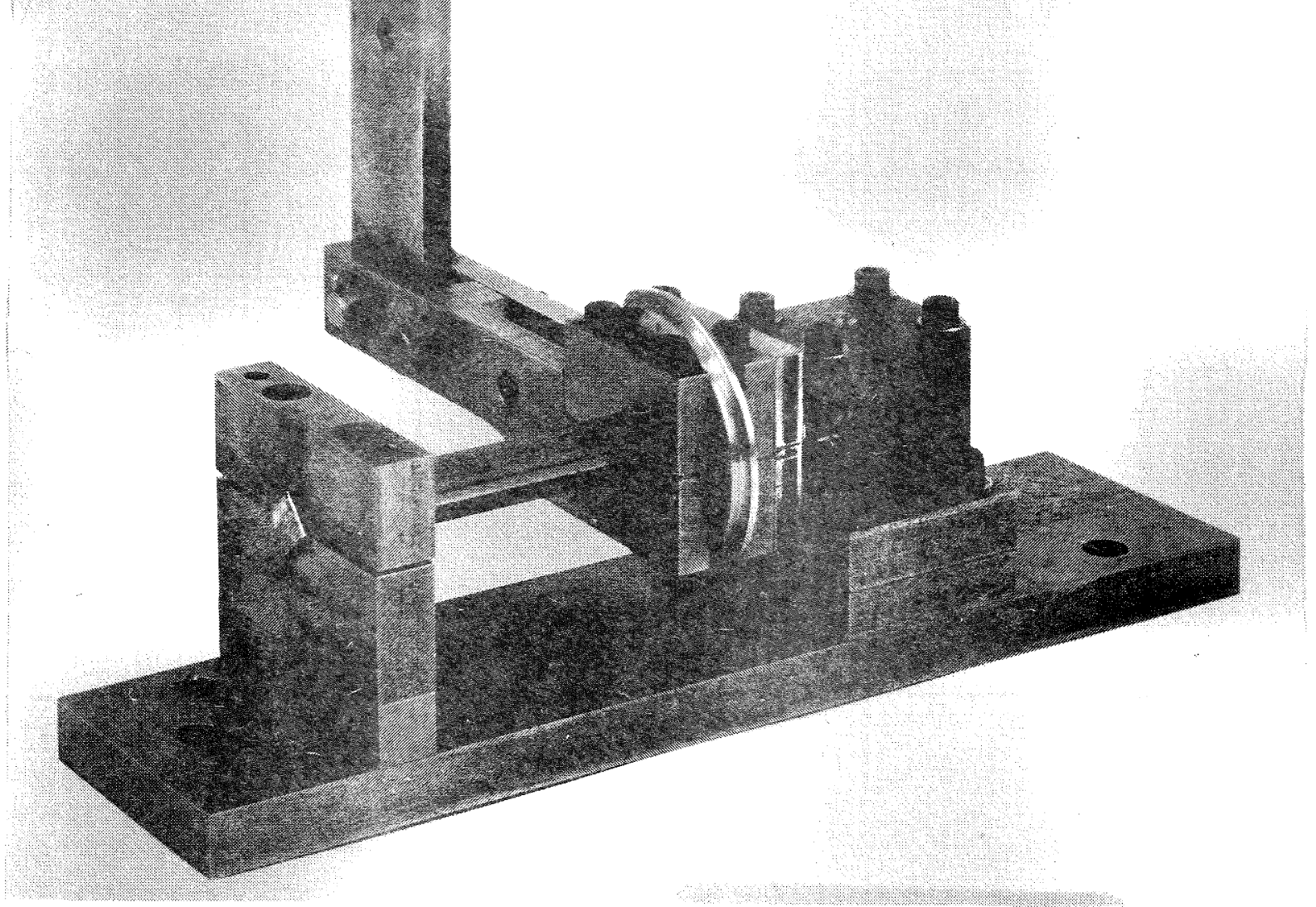

FIG. 9 TEST JIG FOR CYCLIC LOADING IN PUAE TORSION

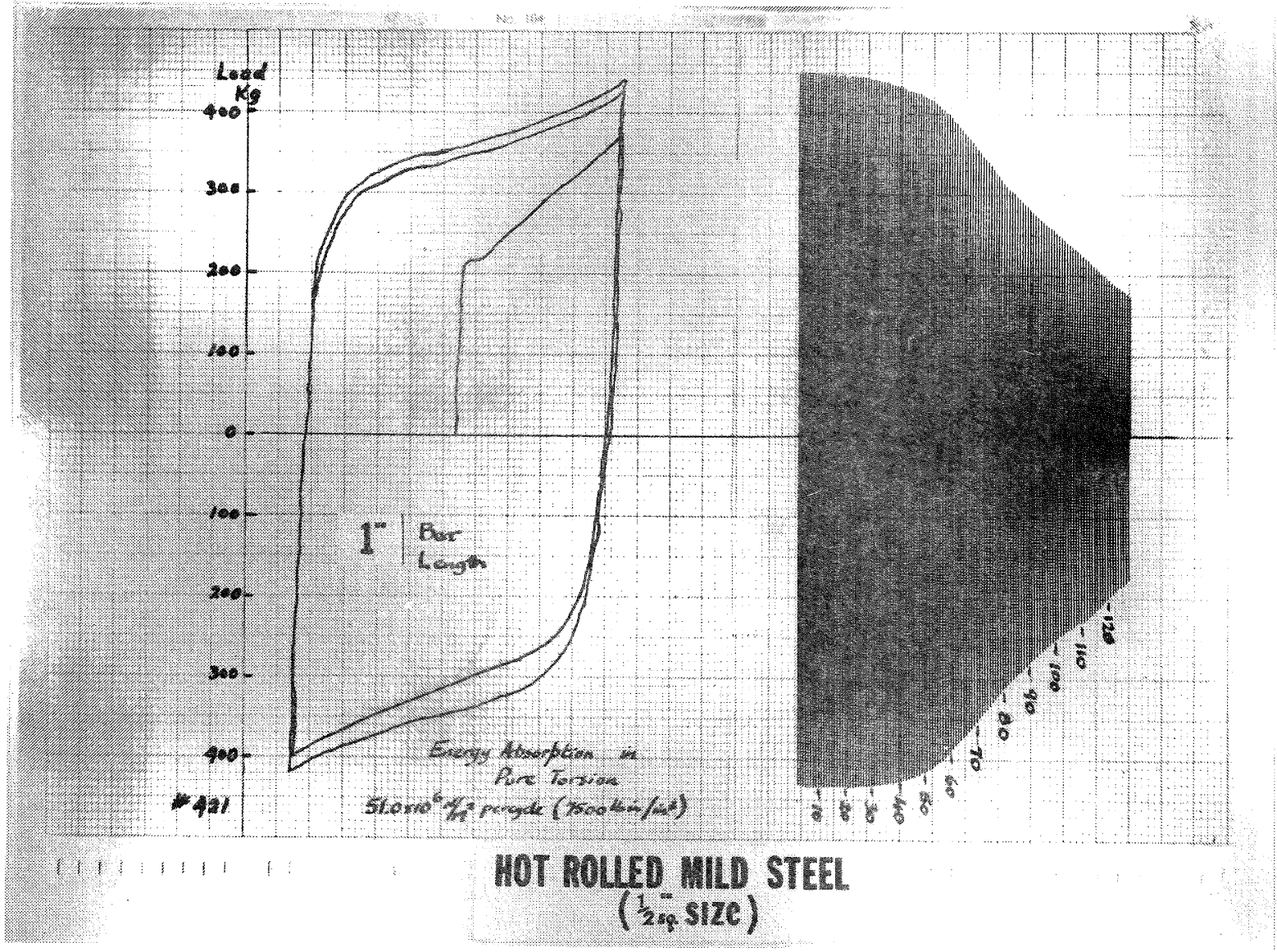
FIG. 10 TYPICAL TEST RECORD IN CYCLIC TORSION SHOWING
HYSTERIS LOOPS AND THE DECAY BEHAVIOR 
82

Torque vs. Plastic Angle of Twist for 'sq. Hot Rolled Mild Steel Bar clear length $3^{\prime \prime}$
Unidirectional loading

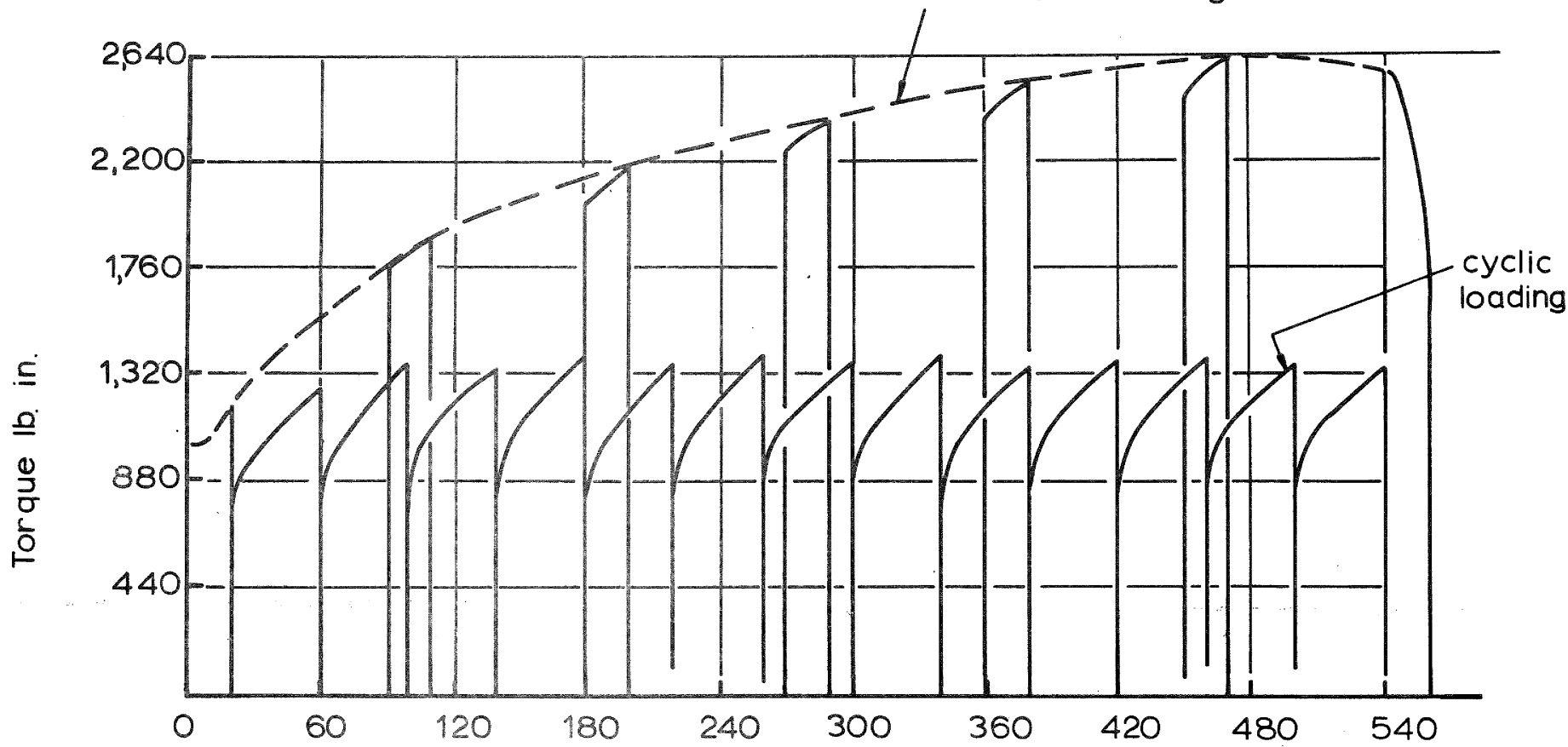

Cumulative Angle of Twist, Degrees

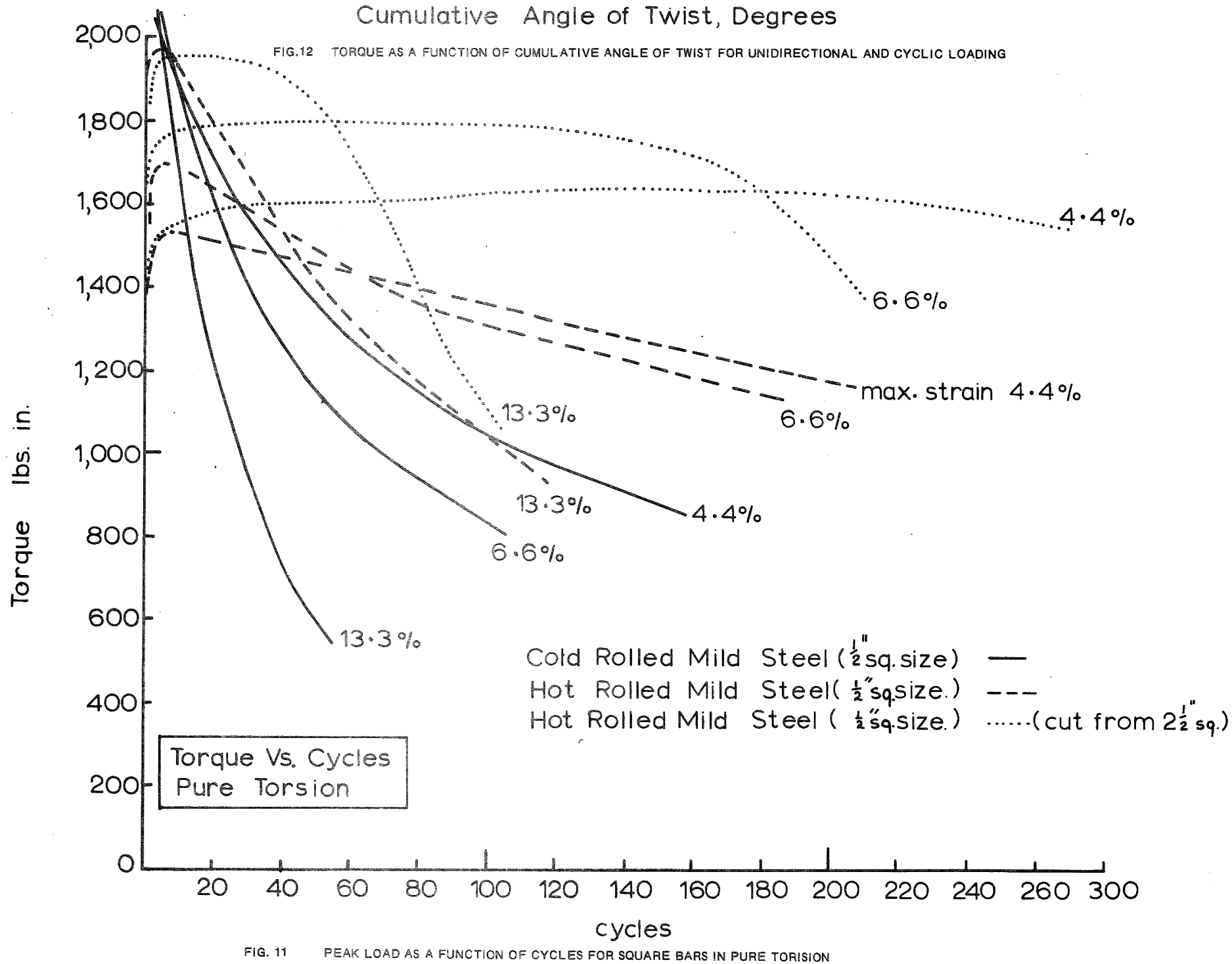




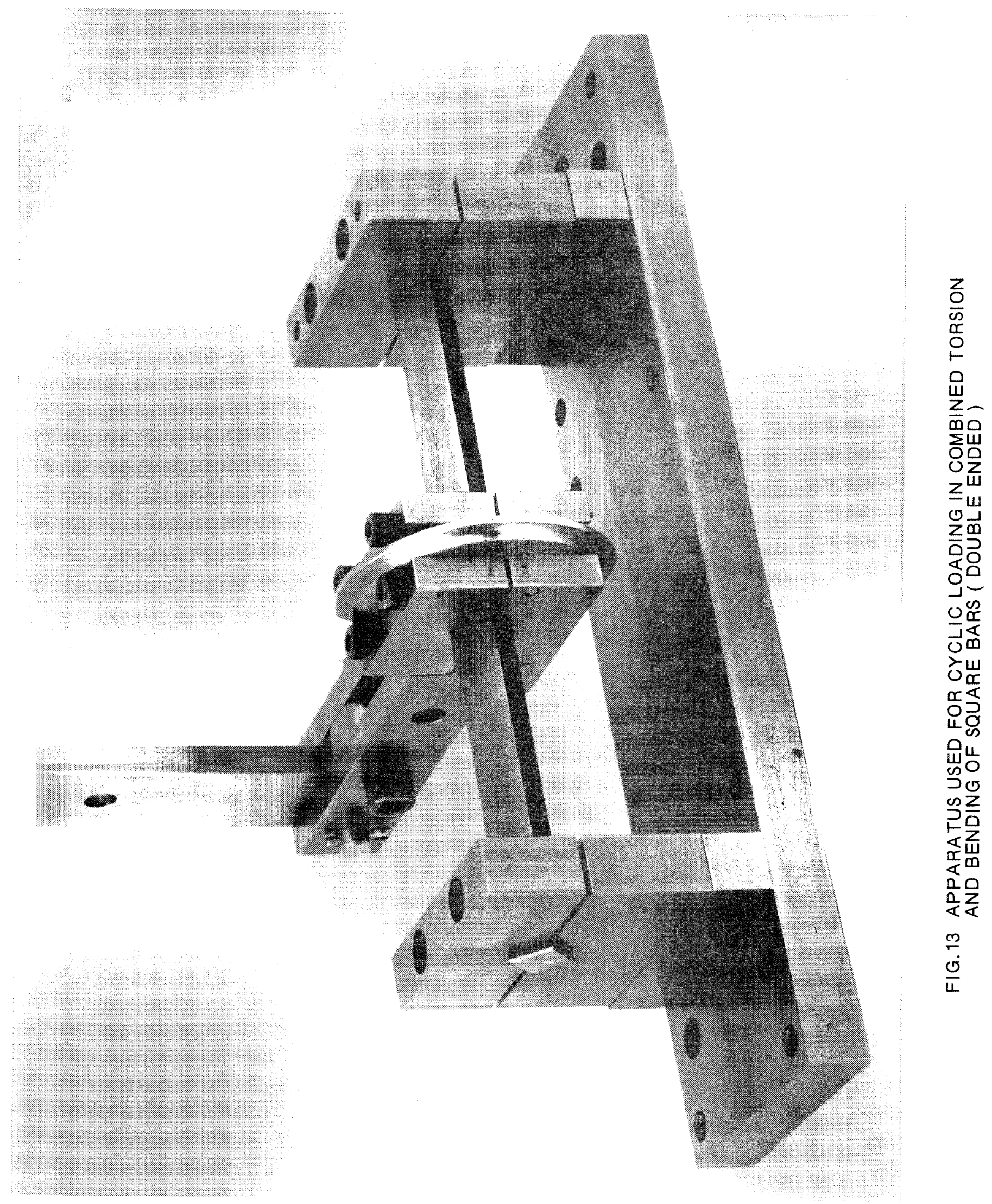




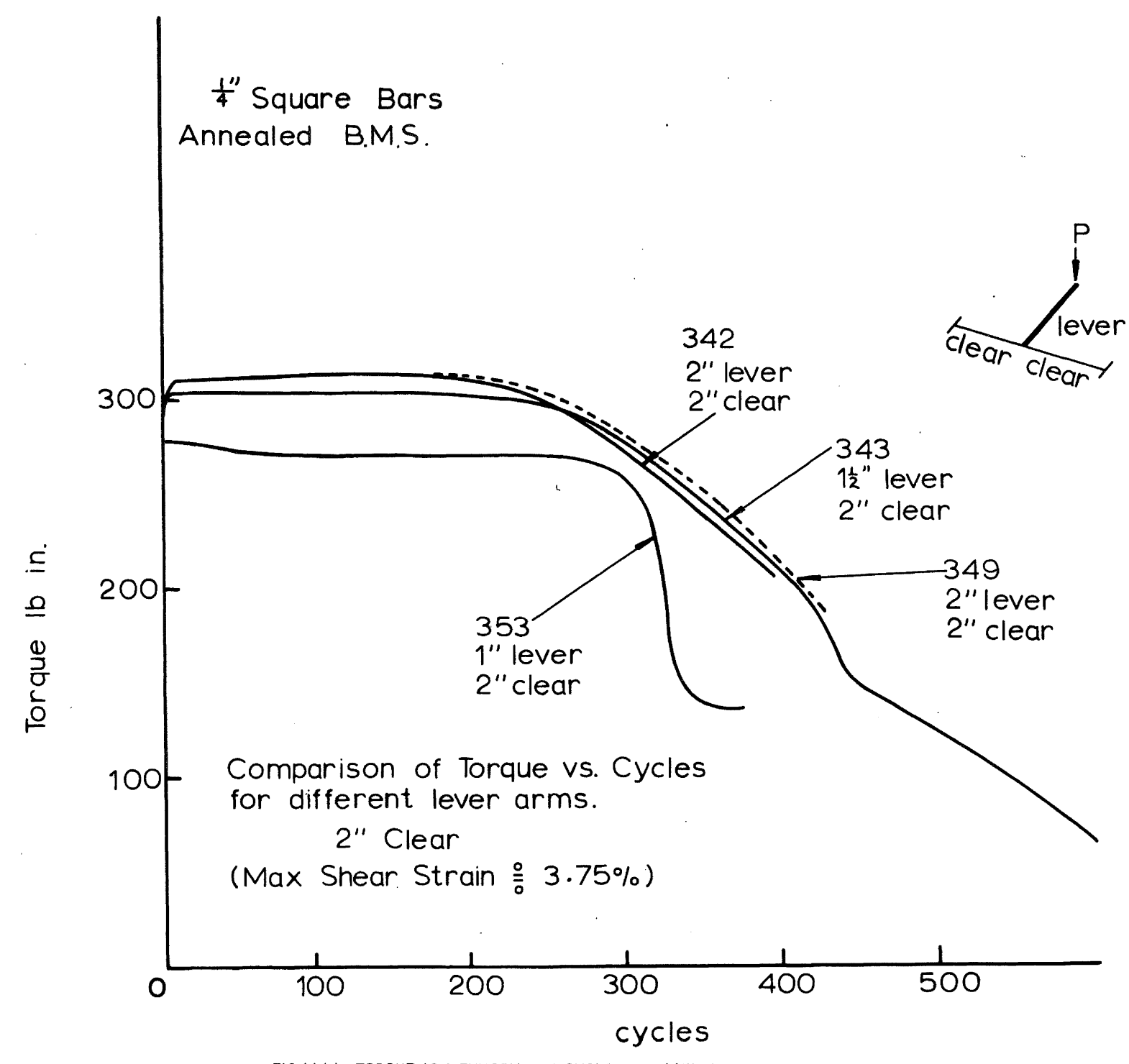

FIG.14 (a) TORQUE AS A FUNCTION OF CYCLES FOR 1/4". SOUARE BARS ( DOUBLE ENDED )
WITH 2" BAR LENGTH AND VARYING LEVER LENGTHS
Square Bars (Annealed)

Torque vs Cycles for

different lever lengths.

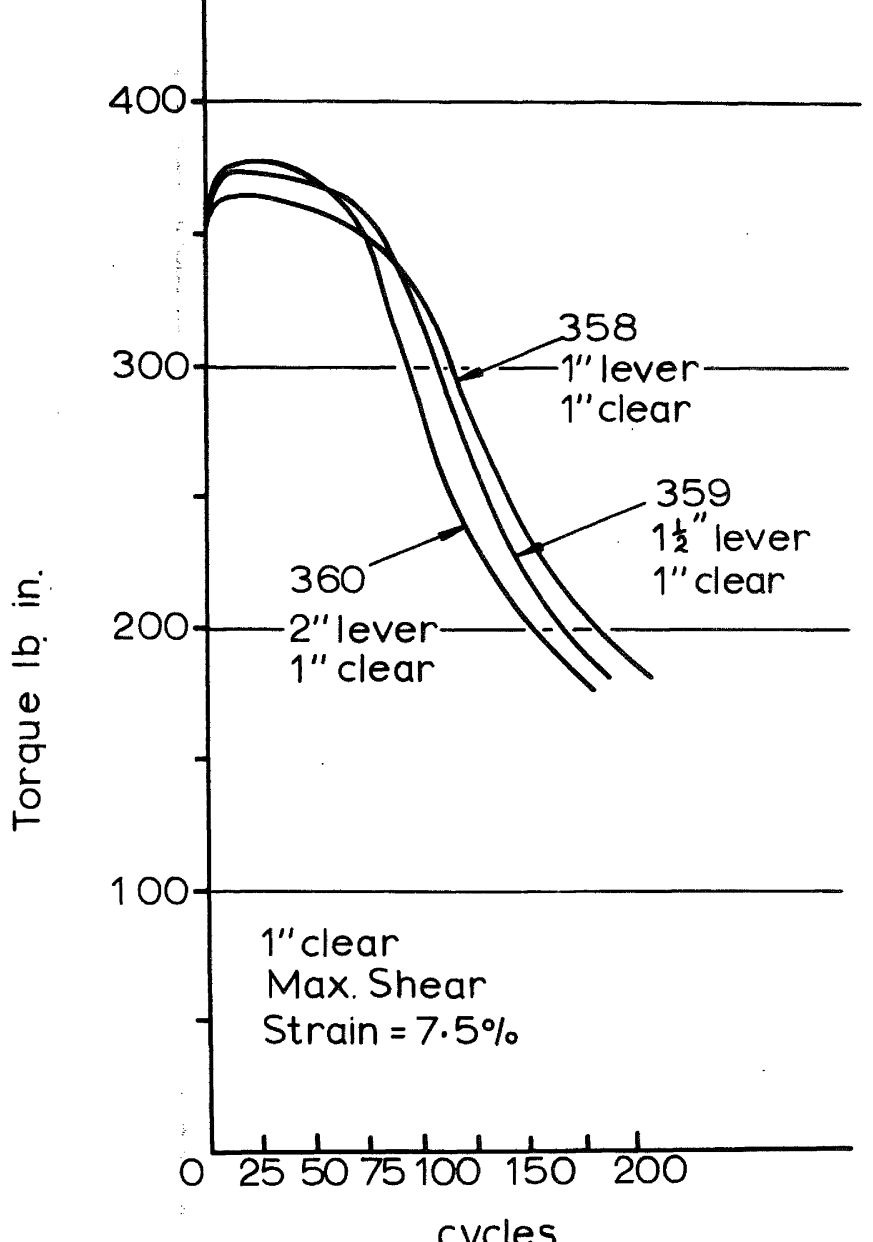

FIG. 14 (b) TOROUE AS A FUNCTION OF CYCLES FOR 1/4". SQUARE BARS ( DOUBLE ENDED) 


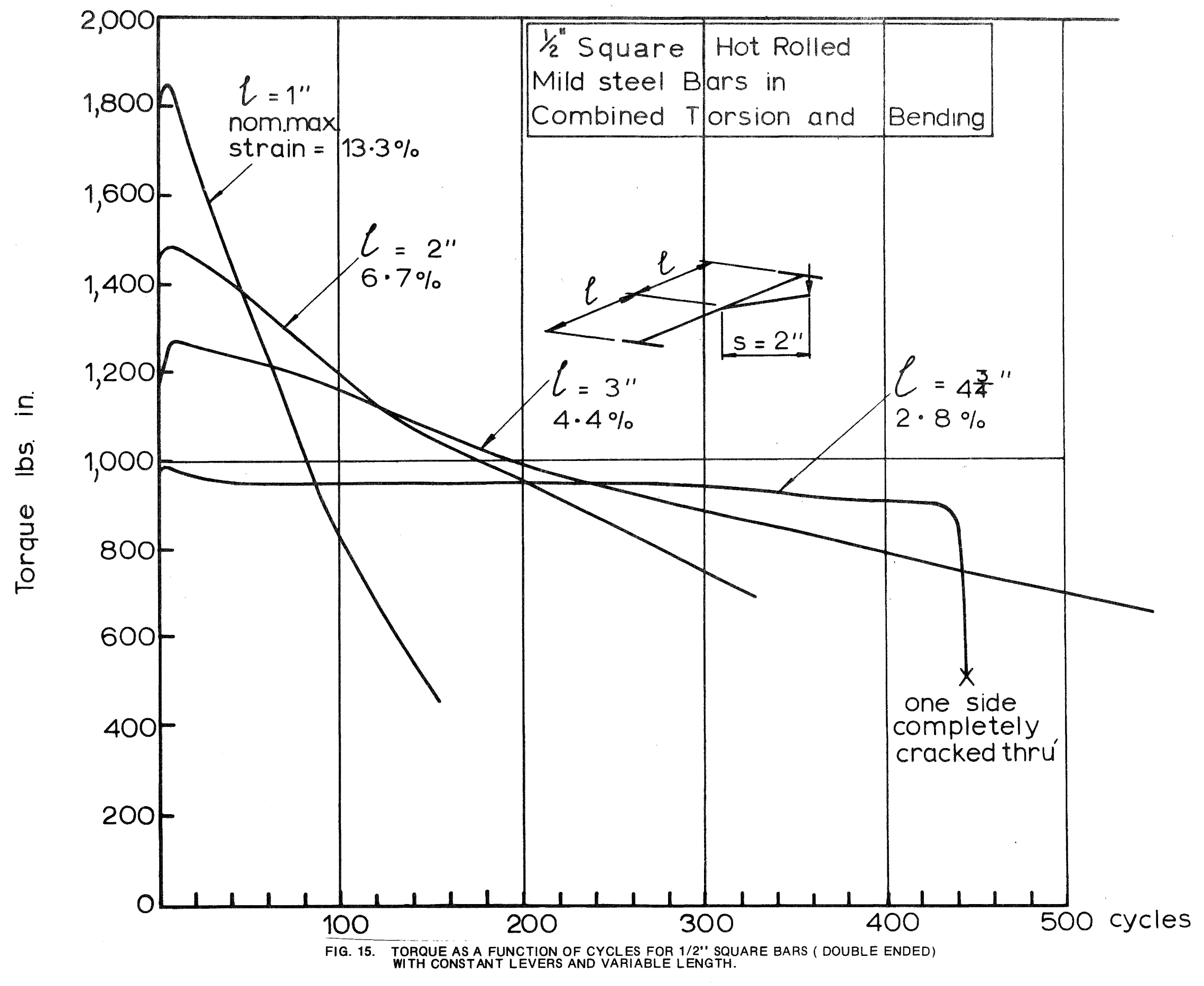




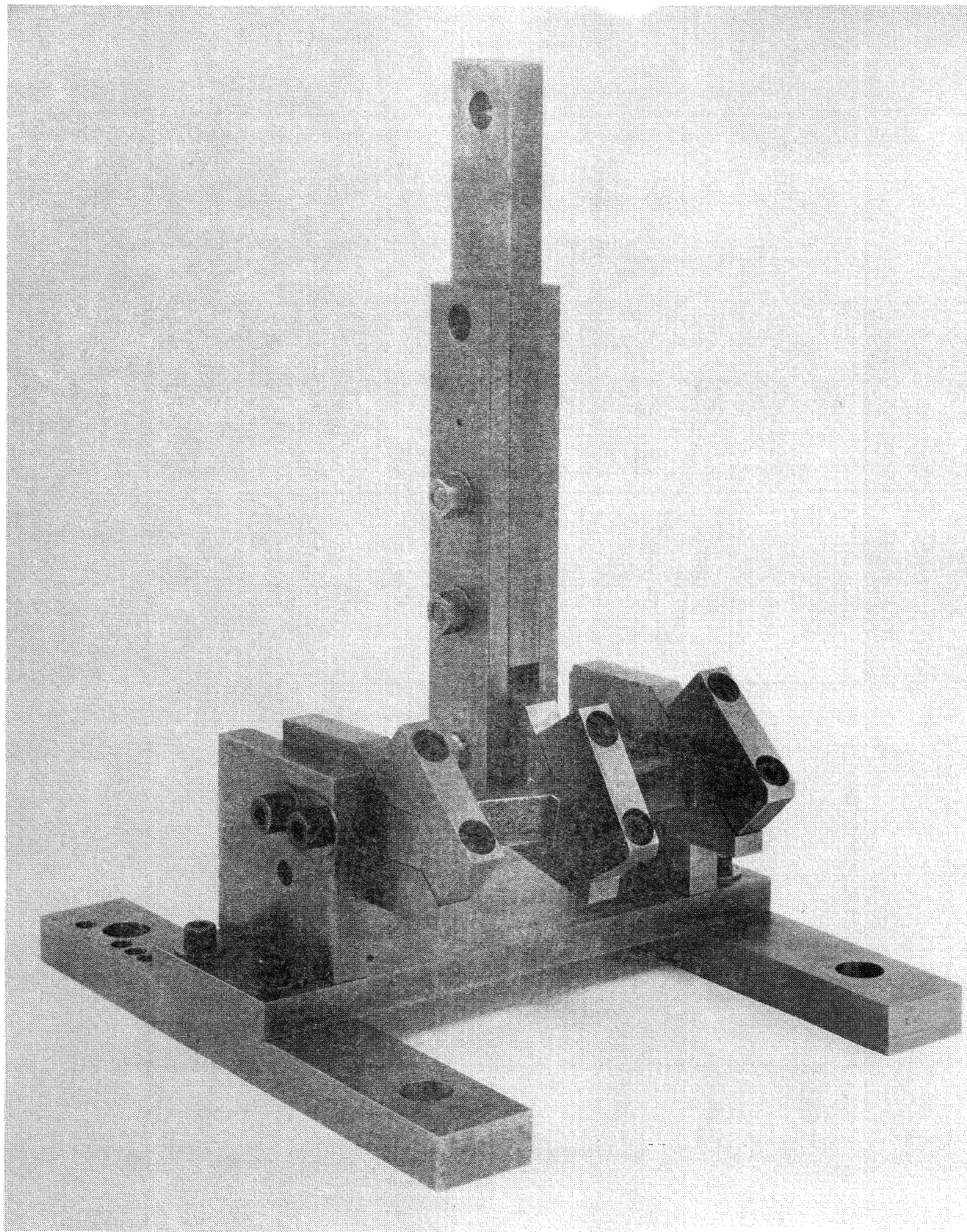

FIG. 16. APPARATUS USED FOR COMBINED TORSION AND BENDING OF RECTANGULAR BARS 


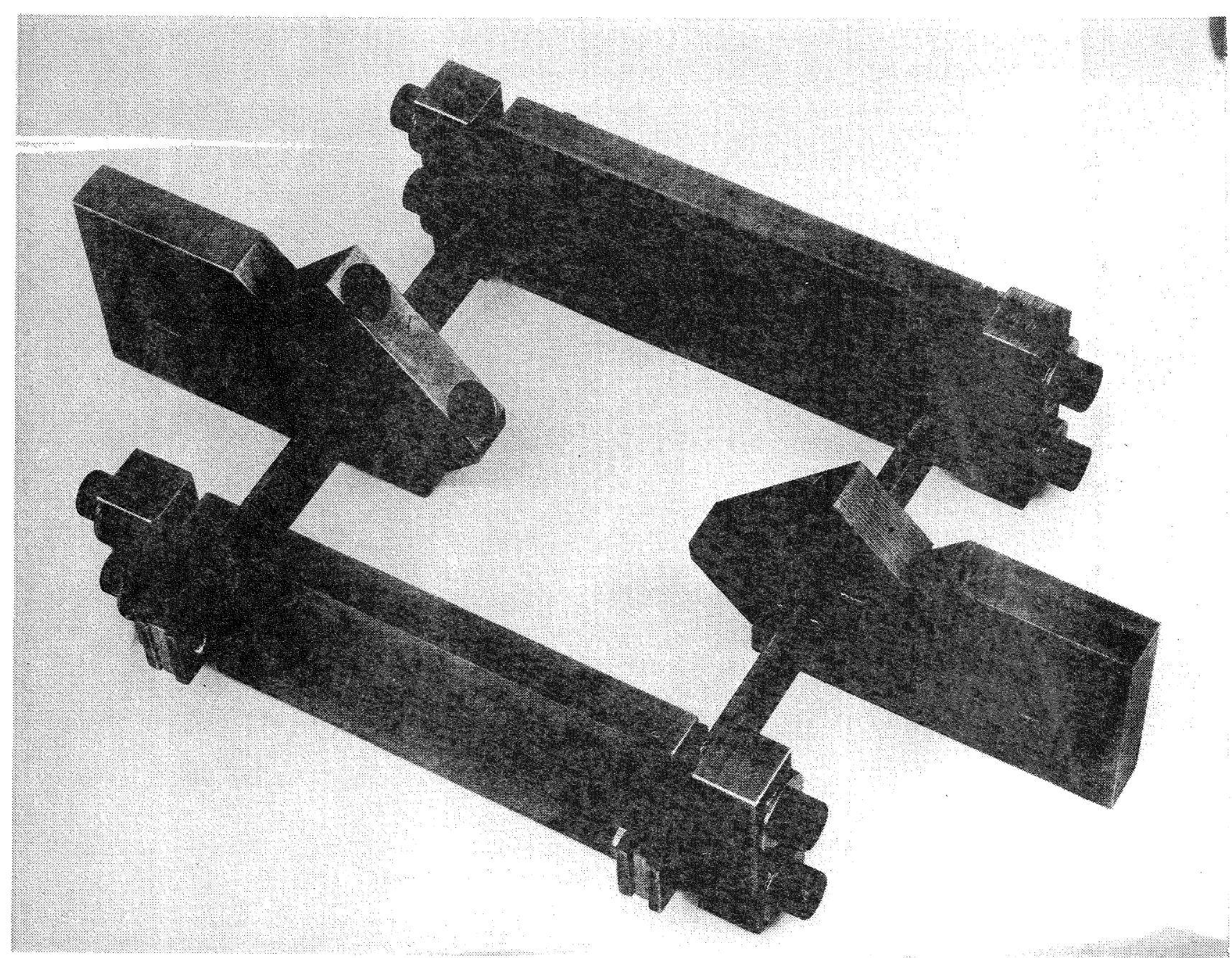

FIG. 17 APPARATUS USED TO INVESTIGATE FLEXUAL ENERGY ABSORPTION.

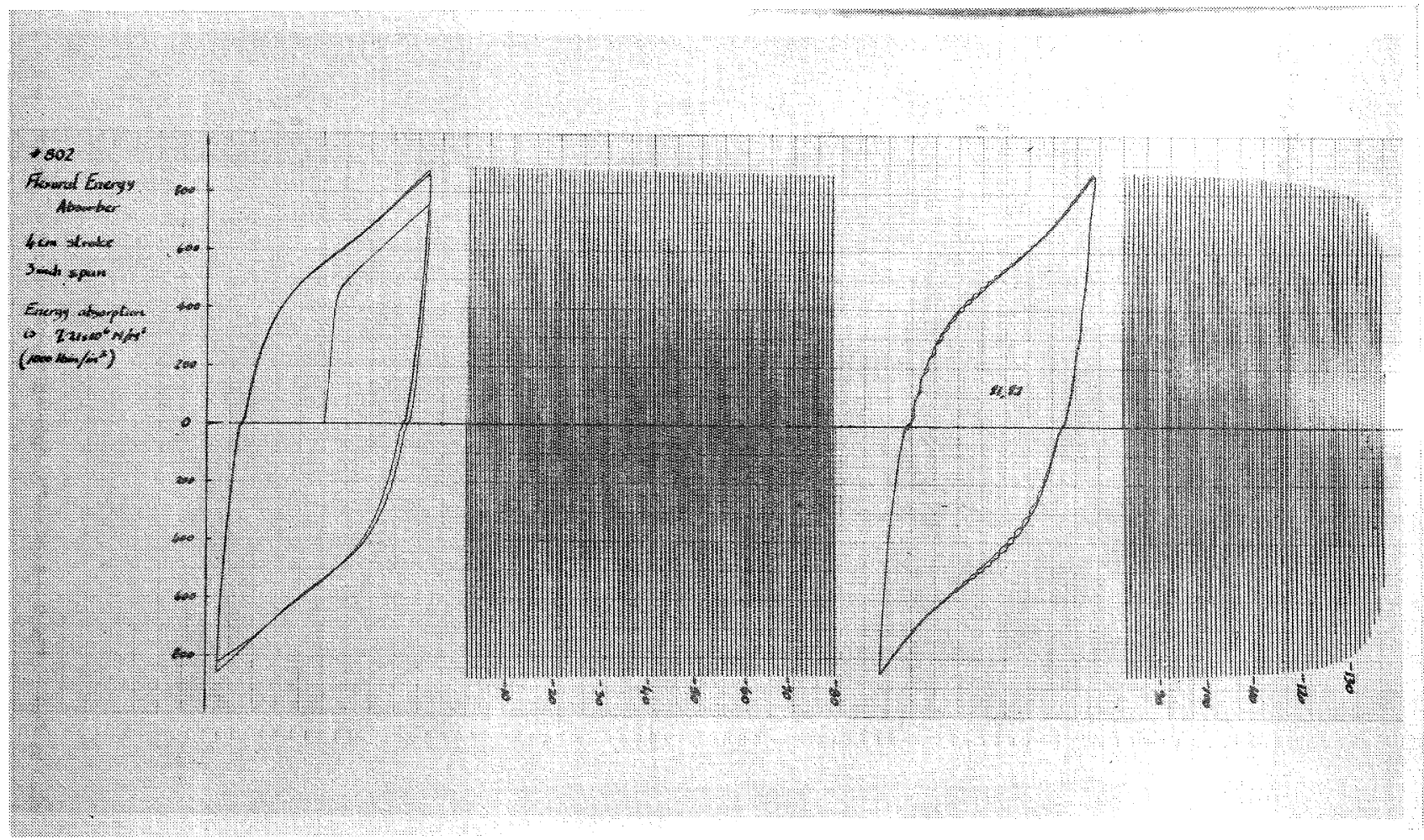

FIG. 18 TYPICAL TEST RECORD IN CYCLIC FLEXURE SHOWING HYSTERIS LOOPS AND RAPID FAILURE 


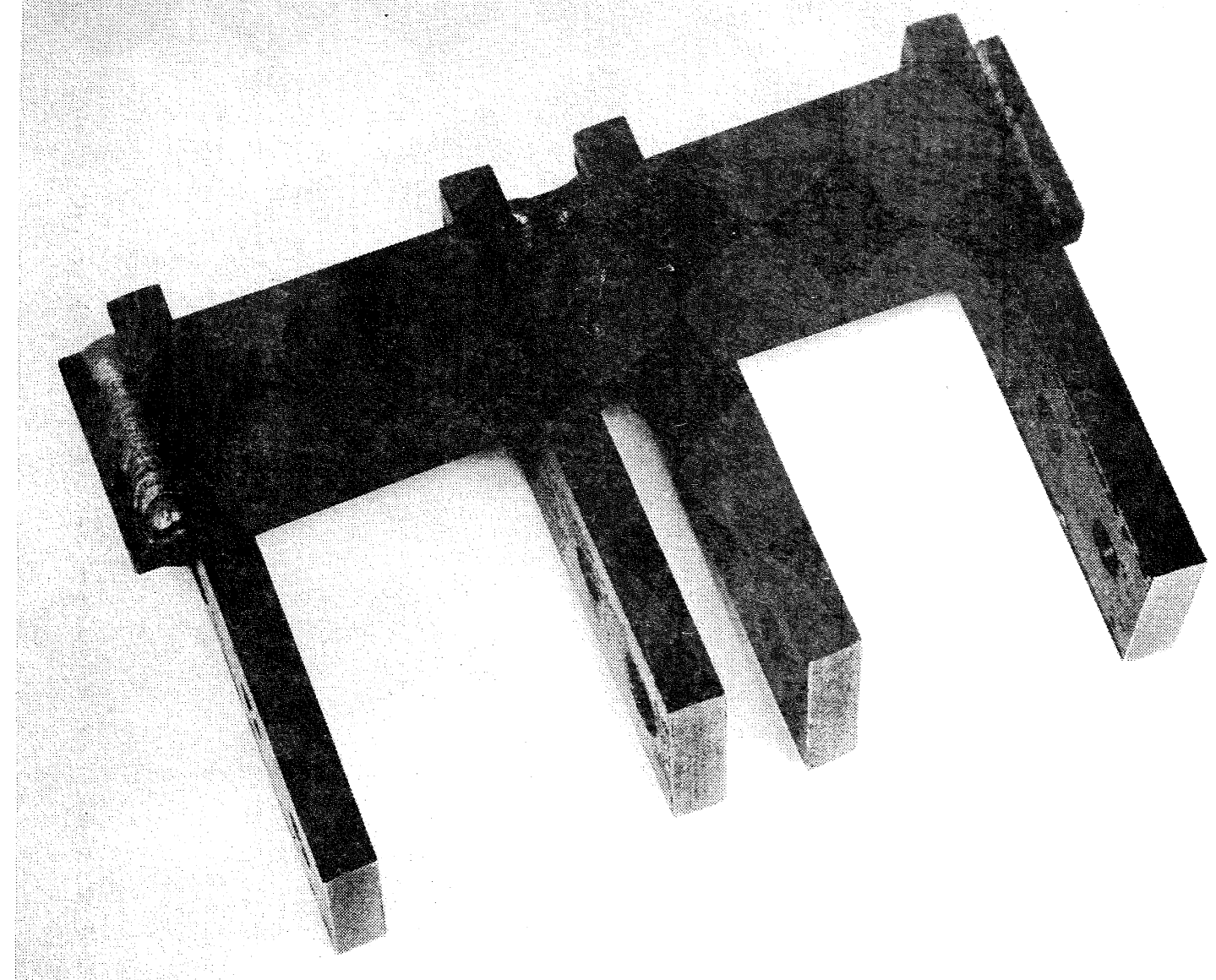

FIG. 20 SCALE MODEL OF DEVICE FOR BRIDGE PIER AFTER TESTING TO 500 CYCLES, SHOWING WELD LOCATIONS AND LONGITUDINAL

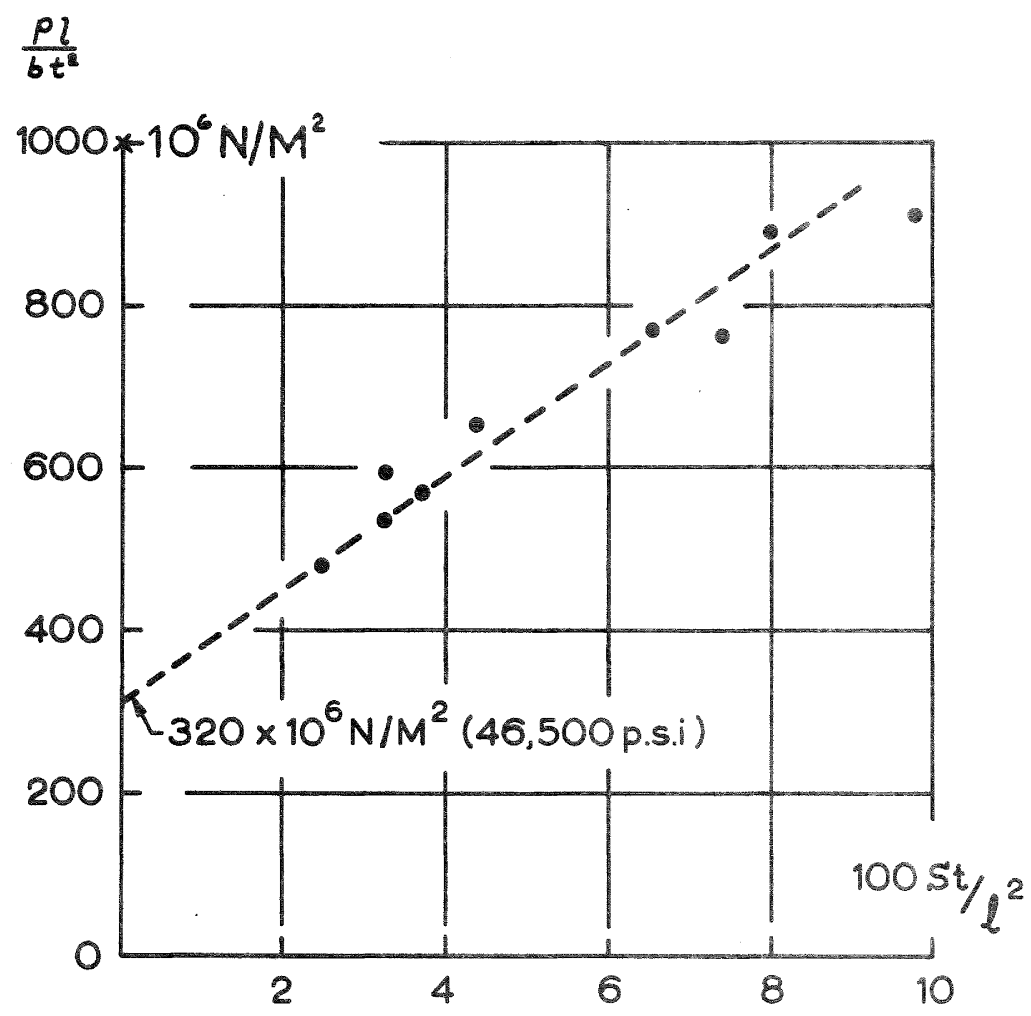

FIG.19 PEAK LOAD AS A FUNCTION OF STROKE IN FLEXUAL TEST 